\title{
Explanatory profiles of models of consciousness - towards a systematic classification
}

\author{
Camilo Miguel Signorelli ${ }^{\mathrm{a}, \mathrm{b}, \mathrm{c}, *, \bigotimes}$, Joanna Szczotka ${ }^{\mathrm{d}, *}$, and Robert Prentner ${ }^{\mathrm{e}, \mathrm{f}, *}$ \\ ${ }^{a}$ Cognitive Neuroimaging Unit, INSERM U992, NeuroSpin, France. \\ ${ }^{b}$ Department of Computer Science, University of Oxford, UK. \\ ${ }^{\mathrm{c}}$ Center for Brain and Cognition, Universitat Pompeu Fabra, Spain. \\ ${ }^{\mathrm{d}}$ Center for Sleep and Consciousness, University of Wisconsin-Madison, USA \\ e Department of Cognitive Sciences, University of California, Irvine, USA \\ ${ }^{\mathrm{f}}$ Center for the Future Mind, Florida Atlantic University, Boca Raton, USA \\ All authors contributed equally to this work
}

\begin{abstract}
Models of consciousness aim to inspire new experimental protocols and aid interpretation of empirical evidence to reveal the structure of conscious experience. Nevertheless, no current model is univocally accepted on either theoretical or empirical grounds. Moreover, a straightforward comparison is difficult for conceptual reasons. In particular, we argue that different models explicitly or implicitly subscribe to different notions of what constitutes a satisfactory explanation, use different tools in their explanatory endeavours, and even aim to explain very different phenomena. We thus present a framework to compare existing models in the field with respect to what we call their "explanatory profiles". We focus on the following minimal dimensions: mode of explanation, mechanisms of explanation, and target of explanation. We also discuss the empirical consequences of the discussed discrepancies among models. This approach may eventually lead to identifying driving assumptions, theoretical commitments, experimental predictions, and a better design of future testing experiments. Finally, our conclusion points to more integrative theoretical research, where axiomatic models may play a critical role in solving current theoretical and experimental contradictions.
\end{abstract}

Models of consciousness | Explanation | Unification | Phenomenology | Integrated information | Global workspace | NCCs | Quality | Quantity

Correspondence: camiguel@uc.cl

\section{Highlights}

- Models of consciousness constitute hypotheses on how consciousness relates to the physical domain.

- Numerous competing frameworks build on different philosophical grounds and favour particular scientific methodologies.

- We compare models based on three analytical dimensions: mode of explanation, mechanisms of explanation and target of explanation.

- Differences in the conception of explanation have empirical consequences: the futility of localization approaches, the potential of second-person methodologies, and different senses of "content" of consciousness.

- Future research needs integrative approaches, where mathematical and axiomatic models may play a critical role.

\section{Introduction}

Models of consciousness set out to provide a principled description of how the physical domain relates to conscious experience (1-3). In the last decades, consciousness researchers put forward an abundance of conceptual and formal proposals, drawing from neuroscience, physics, mathematics, philosophy, or experimental psychology. In an early scientific phase, it is natural to expect many competing models to develop in parallel to each other. A more mature stage should entail a substantial cross-talk between them, aiming at distilling critical similarities and differences between them, extracting precise empirical predictions (4) and lastly, eliminating falsified frameworks through a set of crucial empirical experiments, as presently envisioned in (5).

An alternative would be to demand that competing theories need to converge to a unified, synthesized account in order to make progress $(6,7)$. In the following paragraphs, we posit that there are currently several, serious impediments to both crucial experiments but also convergence approaches. Arguably, more conspicuous and empirically tangible differences in the theories (such as their postulated neural-correlates: prefrontal cortex or posterior hot-zone) derive from much deeper, implicitly held deviations in theoretical and philosophical assumptions. In particular, proponents of different theories seem to substantially disagree on what would constitute a satisfactory explanation of consciousness in the first place. Therefore, the aims of these theories are sometimes different. Once all these discrepancies are fully made explicit, the major models can start to enrich each other in a meaningful way. At least in some cases, theoretical misalignment between the models might boil down to different angles of looking at the same problem.

Although navigating through such a highly diversified theoretical landscape remains challenging, there is hope that one could account for the large variation in the field by using only relatively few axes of comparison. To this date, there have been only a couple of systematic attempts to thoroughly compare the contemporary models of consciousness $(6,8,9)$. Arguably, however, all these endeavours have not gone beyond simply collating the theories' different explanatory targets and their main employed paradigms. In addition, the way the theories have been classified so far (such as targeting either phenomenal or access consciousness (6) or whether 
they are related to the pre- or post-stimulus neural activity) might have created more confusion than elucidation (10-12). In order to identify the most critical points of contention in the field, we first introduce the philosophical landscape (Section 2), then we explicate three crucial directions in which frameworks diverge most noticeably with respect to their explanatory pretense (Section 3). Among these directions we distinguish: mode of explanation (mechanistic vs. unificationist), mechanism of explanation (functional vs. causal), and target of explanation (quality vs. quantity of consciousness). These dimensions are discussed along contemporary models of consciousness, which creates a multi-dimensional explanatory profile for each. We also discuss two empirical consequences of this (Section 4). We conclude by advocating for a more integrative approach, hinting at already existing empirical and theoretical (mathematical) tools (Section 5). We narrow our scope to 14 influential models. While being aware that our selection of models is not exhaustive, we do hope that our work would still spark meaningful discussions and inspire orderly and structured comparisons in the field.

\section{The problem of consciousness}

Philosophy does not solve problems, it rather helps to emphasize and reconceptualize them, making problems amenable to scientific investigation. Therefore, we first look at some of the main concepts relevant to the question of consciousness, which are often implicitly held by current scientific theories.

\section{1. "What-it-is-like" to have an experience}

The idea that consciousness comprises an inner subjective feeling poses perhaps the biggest challenge to any model of consciousness. Explanatory projects in the contemporary neuroscience of consciousness thus often seem to target the notion of "phenomenal consciousness" that goes back to work by Thomas Nagel from the 1970s, emphasizing the "what-it-is-likeness" of conscious experience. Nagel argued that the purely objective study of an entity, such as the one science provides, does not allow any inference about the subjective character of being such an entity. This has sometimes been misconstrued as the claim that a purely subjective phenomenon such as consciousness cannot be studied at all within the objective framework of science and should best be left alone, an idea which has been forcefully disputed by John Searle $(13,14)$.

However, the position that phenomenal consciousness should be the end-all of any scientific theory of consciousness has been contested. Most prominent here is the illusionism proposed early on by Daniel Dennett $(15,16)$, which got traction recently but still comes with its own issues (17-19). A frequent criticism of such illusionist approaches is the charge of being anti-realist about consciousness. Yet, this charge can be finessed (20). What is typically denied by illusionists is the existence of some non-physical essence of conscious experience - the seemingly qualitative nature of experience but not the reality of experience itself. This can, for example, be illustrated with the "multiple drafts model" of consciousness put forward by Dennett (16). If the illusionist claim is understood in this weaker way, the majority of neuroscientists would likely agree. However, it is then not clear how this position would contribute to a scientific understanding of consciousness, effectively arguing against a philosophical straw man.

Another related distinction is the one between the notions of "phenomenal" and "access" consciousness $(21,22)$. The former refers explicitly to its what-it-is-likeness, sometimes assumed to correspond to a "minimal sense" of conscious experience without necessarily requiring reportability $(23,24)$. In particular, some theories of consciousness claim to be about exactly this phenomenal aspect and thus carry a distinct explanatory pretense. The latter notion, "access" consciousness, corresponds to centralized availability for processing of information and the reportability of a conscious experience. It also refers to phenomena that are closely related to consciousness in other aspects (e.g. attention or meta-cognition). It is an open debate in the scientific study of consciousness whether an explanation purely in terms of access consciousness is truly satisfactory or whether it is not in fact the only scientifically rigorous approach $(25,26)$.

Much of the prominence that phenomenal consciousness received as a potential scientific topic can be traced back to the work of David Chalmers who introduced the notion of the "hard problem of consciousness" (27), the difficulty to explain why certain forms of physical information processing should feel like anything at all or how physical and phenomenal facts are related to each other. Chalmers argued against the reducibility of consciousness and initially advocated a "natural dualism" (28). Natural dualists assume that reality is composed of two sets of (irreducible) properties. Chalmers moreover assumed that those refer to two properties of "information", and that the functional (psychological) structure of information processing in the brain is mirrored in the phenomenal structure of consciousness. Chalmers later made the case for "panpsychism" (29-31), the view that consciousness is ubiquitous in nature and serves as the irreducible "intrinsic nature" that grounds physical properties. Panpsychism is related to "dual-aspect monism" that considers consciousness and physics merely as two aspects of a single underlying reality (32). Some dual-aspect monists are panpsychists, though not necessarily so (other dual-aspect monists assume the single underlying reality to be neither of mental nor material but of "neutral" nature (33)).

An alternative way to approach the problem of consciousness is the "biological naturalism" of John Searle (14). While Searle acknowledges the phenomenal character of consciousness, he finds it "obvious" that it emerged from the brain similar to the way bile is produced by the liver. However, to date, no viable mechanism has been identified for this process. The problems for Searle's approach are representative of all materialistic or "physicalist" approaches to consciousness that are discussed later in the paper, at least where they pretend to shed light on phenomenal consciousness. The majority of approaches in the scientific study of consciousness endorses the position of physicalism.

Another monistic response is to invert the hard problem and 
argue that the physical world is a product of consciousness. Idealists, roughly, state that matter exists only insofar as it is represented in consciousness - although idealism in fact comprises a set of many different (heterogeneous but related) views. The idealistic position was once the dominant worldview in much of Western and Eastern culture, but received a massive blow in the 20th century. Most philosophers and scientists do not take this option seriously anymore, although the climate seems to change with more and more scholars advocating such a view (34-38).

Finally, one could try to bracket metaphysical issues in the study of consciousness and instead follow an approach advocated by Francisco Varela. Whereas Chalmers postulated that it seems as if there is a need for "extra ingredients" to physical theory and whereas the various monisms express certain philosophical presupposition, Varela suggested to regard consciousness and brain processes as "mutually constraining phenomena" (39-41) that ground an empirical approach to consciousness. More generally, Varela's "neurophenomenology" is an adaption of an earlier continental approach (known as "phenomenology" $(42,43)$ ) to cognitive neuroscience that seeks to uncover the necessary structures of all experiences (including the ones that give rise to scientific knowledge). Neurophenomenology thereby suspends any metaphysical judgement if possible, thus realizing a methodological desideratum of earlier phenomenologists, who intended to go "back to the things themselves", i.e. back to experience. Whether or not consciousness is in fact an emergent phenomenon, this leaves unanswered the question how explanations in terms of brain dynamics and conscious experience mutually constrain each other, for example, to what extent consciousness is able to influence its physical substrate (44) or how any supposed "backreaction" would manifest itself in scientific data.

Some scientific problems still remain in all of these proposals - even though they come in very different guises. Illusionists need to explain why the illusion of consciousness appears as something real and vivid (the "illusion problem" (17)) and argue that there is in fact no problem of consciousness over and above the problems of "access" consciousness (problems which still need to be solved though). Alternatively, one would need to specify the reductive relation between "phenomenal" consciousness and matter (e.g. solve the "hard problem" and give a model of how consciousness actually emerges from the brain), or explain the causal efficacy of conscious experience.

\subsection{From philosophy to scientific models of con- sciousness}

A framework for the study of consciousness refers to a group of premises and assumptions to guide experiments and interpret general results. More specifically, a model of consciousness conveys concrete hypotheses, predictions, mechanisms, and explanations of the associated phenomena. A proper theory for consciousness consists, by contrast, of a set of explicit (and often formalized) systematic premises plus a concrete model to enable the testing of (empirical or theoretical) pre- dictions and eventually its implementation and manipulation. The approaches discussed in this paper correspond to models that mostly operate on implicit assumptions. Even though, they do not resemble proper theories, in the sense just outlined, we will use both the terms "theory" and "model" interchangeably in the remainder of this article to better conform to the literature.

A first step to better understand models of consciousness is to make explicit their underlying philosophical assumptions. These assumptions inform and influence models of consciousness. In figure 1, we summarize the main relationships between philosophy, early and modern models of consciousness.

In this article we consider early models such as the mechanistic model of Crick and Koch (CK), Dynamical Core (DC), Multiple Drafts Model (MDM), Orchestrated Objective Reduction (OrchOR), Global workspace (GW), ThalamoCortical loops and Sensorimotor Couplings (TCL), the dualist proposal by Beck and Eccles (BE), and Enactive and Radical Embodiment (ERE). Modern models are Global Neuronal Workspace (GNW), Higher-Order Thought Theory (HOT), Recurrent Processing Theory (RP), Predictive Processing and Interoception (PP\&I), Integrated Information Theory (IIT), Attention Schema Theory (AST), Conscious Agents Networks (CAN), and Temporo-spatial Theory of Consciousness (TTC).

Early models typically inform later ones, sometimes via direct succession (e.g. GW/GNW), or via integration of concepts developed in previous models (e.g. TTC). Models may also initiate dialogues and remain under dynamic influences with each other. For example, both postulates of GNW and IIT do remain consistent to some extent with mechanisms put forward by the predictive coding approach (PP\&I). Sometimes, the relation between different models or theories has more of an implicit nature. For example, IIT is sometimes thought to express some form of panpsychism, though this is done rather implicitly, inferred via analyzing IIT's basic premises.

\section{Method of classification}

Our initial examination of the current models of consciousness involves placing every theory within three orthogonal dimensions corresponding to the positions they espouse with regard to explanation. The first axis stands for the mode of explanation assumed by the model (mechanistic vs. unificationist), the second for the mechanism of explanation (functional vs.causal), and the third for the target of explanation (quantity vs. quality of consciousness). This classification results in "explanatory profiles" for each theory, which accounts for a substantial amount of variance in the theoretical landscape.

Importantly, the mode of explanation is not to be conflated with a mechanism of explanation, i.e. while the mode informs about the ultimate aim of the explanation (what constitutes a satisfactory answer to the "why" question), the mechanism demonstrates which particular tool can get us towards that predefined aim (i.e. the "how" question). 


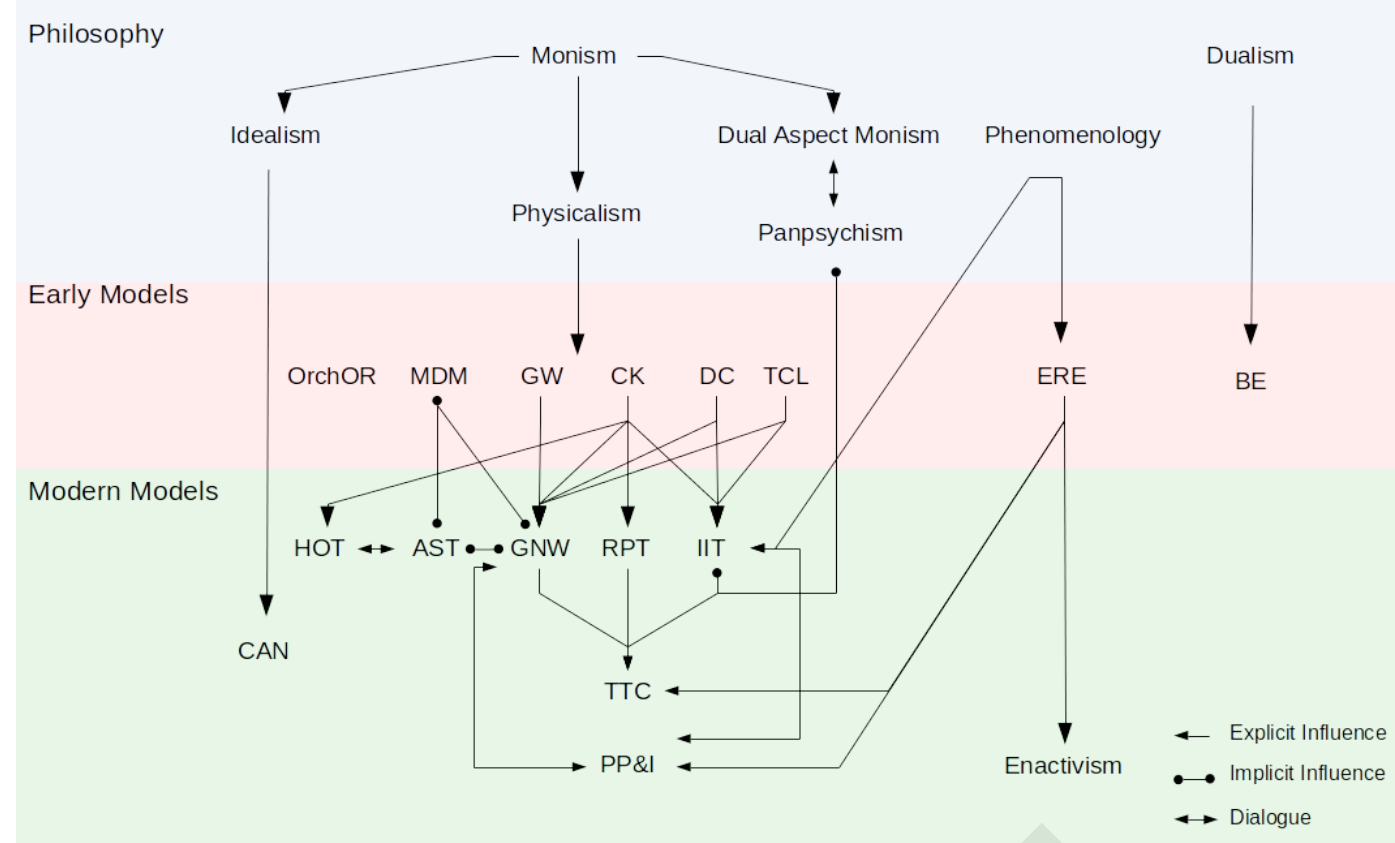

Fig. 1. Philosophy and models of consciousness. Relationships and influences between philosophy, early and contemporary models of consciousness. Acronyms stand for: Crick and Koch (CK), Dynamical Core (DC), Multiple Draft Model (MDM), Orchestrated Objective Reduction (OrchOR), Global workspace (GW), Thalamo-Cortical loops and Sensorimotor Couplings (TCL), Beck and Eccles (BE), Enactive and Radical Embodiment (ERE), Global Neuronal Workspace (GNW), Higher-Order Thought Theory (HOT), Recurrent Processing Theory (RP), Predictive Processing and Interoception (PP\&I), Integrated Information Theory (IIT), Attention Schema Theory (AST), Conscious Agents Networks (CAN), and Temporo-spatial Theory of Consciousness (TTC).

\begin{tabular}{lll}
\hline Axes & First Direction $(+)$ & Second Direction $(-)$ \\
\hline \hline Mode of explanation & Mechanistic & Unificationist \\
\hline Mechanism of explanation & Causal & Functional \\
\hline Target of explanation & Quality & Quantity \\
\hline
\end{tabular}

Table 1. Axes for a three-dimensional classification map with two opposite directions per dimension, represented by positive or negative values. These axes were later used to score models of consciousness, see details in supplementary section 7 .

\subsection{Mode of explanation}

One of the most important hallmarks of a successful theory is its explanatory power. Nonetheless, the very notion of explanation (what it means to successfully explain something), despite its deceptive simplicity, can be unpacked as highly heterogeneous (45-52). In particular, the very notion of "explaining consciousness", although ubiquitous in the literature, constitutes a deceptive "umbrella term", under which one can identify strikingly different theoretical goals. That "consciousness" is frequently used as an umbrella term for various mental phenomena has been often stated in the literature (e.g. (53)). Here we wish to emphasize that the same is true for the seemingly innocent notion of its "explanation". The field of consciousness science has been flooded with numerous works contemplating whether the full explanation of this phenomenon is even feasible (54-56). Therefore, we focus on two alternatives that seem particularly relevant in the domain of consciousness studies: mechanistic approaches and unification $(46,50)$.

A mechanistic approach posits that a particular occurrence is explained once we demonstrate how it "fits into" the presumed spatiotemporal causal structure of the world, i.e. to explain an event is to identify its cause $(46,57)$. This is typically achieved via referring to the transmission of a coun- terfactual and local modification (a "mark") of the associated physical, typically spatiotemporally continuous, process (49).Mechanistic accounts typically subscribe to a realist notion of causation that grounds the explanation, prediction, and other inferences (58). A theory of consciousness that holds the mechanistic view would accordingly imply that the satisfactory explanation of subjective experience requires meticulous unfolding of the chain of causes and effects occurring in the nervous system that leads to a conscious experience of some kind. Such a position imposes a strictly empirical agenda, investigating which neurophysiological events precede and "give rise" to a conscious experience (59). Importantly, the driving force behind such accounts is a philosophical assumption that such a chain of causes is independently given at some objective level of description at some spatiotemporal scale (e.g. of the brain). Naturally, these frameworks tend to cluster together under branches of ontological or methodological reductionism.

On the other hand, the unificationist stance seeks to provide a unified account of a range of different phenomena or laws $(60,61)$, given causal or non-causal explanations $(46,57,62)$, which were previously thought to be unrelated - or related in a mysterious or seemingly arbitrary way (core historical examples are Maxwell's unification of electricity and magnetism 
or Newton's unification of terrestrial and celestial motion). Explaining consciousness under the unificationist framework would give priority to demonstrating how the phenomenon of consciousness is embedded into a parsimonious, coherent framework. As a result, the unificationist seeking a satisfactory explanation would be inclined to associate less with empiricism, and more with formal tools, mathematics and nonreductive philosophy. On the other hand, unificationist explanations have been argued to be most relevant for physics but at odds with biology and neuroscience $(63,64)$.

While mechanistic accounts, implicitly or explicitly, always assume the realist notion of causation in space and time, unificationist accounts postulate that explaining consciousness cannot be exhausted by studying the spatiotemporal chain of causes and effects localized in the brain. In particular, assumptions about the causal order and spatiotemporal descriptions are often being put on hold, and treated as an explanandum (a phenomenon to be explained) rather than as explanans (the grounding of explanation) (65). Causes, at this point, can be regarded as explanatory postulates or theoretical hypotheses that do not exist independently of the explanations that describe them $(58,65)$. Specifically for the science of consciousness, it should also be made clear how or why consciousness is related to the explanation of such causal chains (for example, by arguing that causal orders exist only within consciousness).

Numerous examples show that both types of explanation have contributed to significant progress in science $(49,65)$. Our aim is not to assess which approach produces better explanations, but to simply recognize that different frameworks of consciousness will be inclined to differ already on this very basic assumption.

\subsection{Mechanism of explanation}

We define the term "mechanism" after Illari \& Williamson as "entities and activities organized in such a way that they are responsible for the phenomenon" (66). This way of defining the term is independent from any specific theory of causation. Numerous examples exist where explanations can be purely mathematical, the role of causation being denied, or simply ignored. $(57,62)$.

In the context of consciousness science, an increasingly popular division, introduced in (67) and specifically addressing different kinds of mechanisms, distinguishes explanations as either functional or causal. The stance of functionalism primarily states that consciousness can be generated as long as a particular function is realized (68), without any specific constraint on the exact causal machinery behind it. In principle, any system may become conscious as long as it executes the functions associated with conscious experience. On the opposite side, causal theories do not necessarily unsubscribe from the view that a particular function might be typically associated with consciousness, but the burden of explanation is placed on how such a function is implemented: establishing what and how elements of a system interact. These theories seek relevant causal relationships within the model's target system(s) (62). In those terms, causal models support the idea that only a system with the right causal relationships will lead to conscious experience.

One could further illustrate this distinction by introducing the idea of a structure-preserving map $(M)$ between two objects. Causal models insist that the causal system's structure $(S)$ explains consciousness, $M: S \rightarrow C$, where the arrow refers to a mapping that preserves system structure (whether or not a particular and objective spatiotemporal structure is the most relevant for analysis). Functional models, however, would argue that the functional structure of a system $(F)$ explains consciousness, $M: F \rightarrow C$, and thus it is the function that is preserved by the arrow. These two types of models appear exclusive, in the sense that $S$ and $F$ are different objects. However, if we focus on the nature of the map, independently of their objects, the difference becomes a question of "degree". Causal theories usually assume there is only one way to preserve the causal structure and the phenomenology of subjective reports. This is tantamount to postulating an isomorphism between domains (there exists only one such arrow) (69); whereas functional theories would claim/assume that there are multiple ways (arrows) to preserve the function and therefore giving rise to consciousness, i.e. $M^{\prime}, M^{\prime \prime}, M^{\prime \prime \prime}$, etc.

Superficially, mechanistic accounts and causal models seem to overlap, as both axes refer to the vocabulary of causation. To avoid any potential confusion or apparent contradiction, it is critical to recall our distinction between the aim and tool of explanation (which could be referred to as "metaphysical" and "pragmatical" commitments of the theory, respectively). While mechanistic explanations subscribe to the realist notion of causation, causal models do not necessarily do so and could merely use causes (rather than functions) to unfold the relevant interactions within the target system. In principle, they could still maintain that causes are not "the only" explanandum, in the sense that explaining them still wouldn't suffice to explain consciousness. Thus, a model can be nonmechanistic and causal at the same time without contradiction.

\subsection{Target of explanation}

Lastly, the target of an explanation corresponds to the aspects of a particular phenomenon that scientists intend to explain. The most basic distinction that emerged over the last decades is the one between quality and quantity. The quality of consciousness is what makes consciousness feel the way it does (cf. also Section 2.1), and the quantity corresponds to what makes the system conscious rather than unconscious. A model targeting quality should therefore account for why any stimulus should feel a particular way, what makes an experience spatial, visual, auditory, painful, or temporal, while a model targeting quantity intends to account for global markers differentiating conscious vs unconscious systems.

A full-fledged theory of consciousness needs to explain both the quantity and quality aspects of subjective experience. Several theories tend to focus exclusively on global markers differentiating conscious vs unconscious systems; and the problem of quality in such cases is delegated to the ex- 
ternal world (i.e. sensory cues feel the way they do solely because they 'carry' their quality from the environment, or stimulate 'correct', labeled receptors). However, there are many, conceptual discussions, each pointing to a specific problem of such a "delegation"; see arguments on brains in vats (70), inverted spectrum (71), actual cases of perceptual variation (72), the fact that sensory characters correlate much more with neural patterns than anything else in the external world (73), dramatic perceptual alterations in psychedelic experiences (74), perceptual illusions, and the generic non-preservation of phenomenal and environmental structure (75), etc. A much more challenging project would strive to explain why an experience feels the way it does, for example based on the internal architecture and dynamics of the brain, without referral to the external world as something that 'stores' or 'produces' any qualities (but see (76)).

\section{Classifying models of consciousness}

According to the analytical dimensions defined in the previous section, we now classify and discuss selected models of consciousness in a three dimensional map (Figure 2). This classification intends to illustrate our framework. It is a provisional attempt based on quotations and a rough score that provide support to our discussion. We have first focused on reviewing the relevant articles that describe selected theories. Consequently, we have scoured representative works for statements pinpointing what a satisfactory explanation would look like according to each theory. We have then determined numerical values along the dimensions specified in the previous section (see supplementary sections 6 and 7).

\subsection{Mode of explanation}

Based on our classification, we unpack the explanatory profile of each theory. We have found individual discrepancies, most of the theories leaning clearly towards one or another mode. Some frameworks, including GNW, and HOT, gave us consistent clues to classify them under the mechanistic cluster. A statement that would drive us to the mechanistic classification could be, for example, the following statement by Rosenthal, a proponent of HOT: "we understand something only when we can explain it, and explaining a natural phenomenon typically if not always means locating it in its distinctive causal nexus" (77), or by Dehaene, a proponent of GNW: "tools of cognitive psychology and neuroscience may suffice to analyze consciousness" (78). On the other hand, unificationist propensities are more apparent in frameworks such as IIT: "IIT provides a principled explanation for several seemingly disparate facts about the PSC [Physical Substrate of Consciousness]"; or PP: "... it could unify existing approaches under a single overarching principle (i.e., the FEP)" (79). Such unifying tendencies are also expressed by proponents of AST, who aim for a "standard model of consciousness" (76) by taking a deflationary stance on the reality of consciousness or, on the other extreme, by proponents of CAN: "if we want to go beyond this 'applied science' and understand the true nature of the mind and the reality beyond it, we can't look to neurons or brains" (80). The full list of relevant quotes, justifying each model's classification can be found in Table 2.

This first dimension clearly constitutes a parsimonious dividing force, introducing tensions between the models' individual goals. Arguably, identifying which mode of explanation a theory supports can also predict how a certain theory would pragmatically proceed in its investigations. Although both groups of theories would not deny the relevance of empirical research, the mechanistic models would take on a cautious "bottom-up" approach, withholding the drawing of any firm conclusions without substantial accumulation of incoming data (81). Unification accounts, on the other hand, would be much more prone towards a "top-down" approach, giving priority to those empirical predictions which can make sense of seemingly disparate phenomena from the perspective of the framework itself.

\subsection{Mechanism of explanation}

There is a marked difference in which explanations can provide explanatory power, by either concentrating on overall functional roles, or by describing network parts and the interactions between them. Pertinent examples for functional theories are HOT and GNW, according to which, consciousness can arise in a physical system as long as it realizes "metarepresentation" or "global broadcasting", respectively. On the other hand, models such as IIT and RPT lean towards elucidating the structure of causal interactions at the level of network analysis. For a full list of relevant quotes disclosing either functional or causal inclinations in explaining consciousness, see Table 3.

Although we believe that most theories do explicitly or implicitly differ in these explanatory assumptions, Fahrenfort and van Gaal point out that most empirical theories would eventually aim at explanations involving causal implementations, rather than functions (82). In line with that view, we have indeed come across many examples in which models of consciousness, even those labeled as functional, in actuality resort frequently to the language of causal interactions. For example, as stated by Rosenthal: "On the HOT hypothesis, a conscious state is a compound state, consisting of the state one is conscious of together with a HOT. So the causal role a conscious state plays is actually the interaction of two causal roles: that played by the state itself and that played by the HOT" (77). Another relevant instance could be predictive processing theory (PP). Despite having been classified as functional in (67), one variant of PP clearly states that implementing the adequate computational/functional principles is only a necessary, but not sufficient condition for consciousness. As explicitly mentioned by Wiese and Friston in (79), computations need to be physically instantiated in the right architecture and not all virtual machines that realize approximate Bayesian inference should be considered conscious. The reason they give is that a Markov blanket of the physical system must be based on the system's dynamics, and the dynamics strictly depends on the system's structure. That drives us to conclude that a popular framework has recently moved significantly away from functionalism and can now 


\section{Classification map}

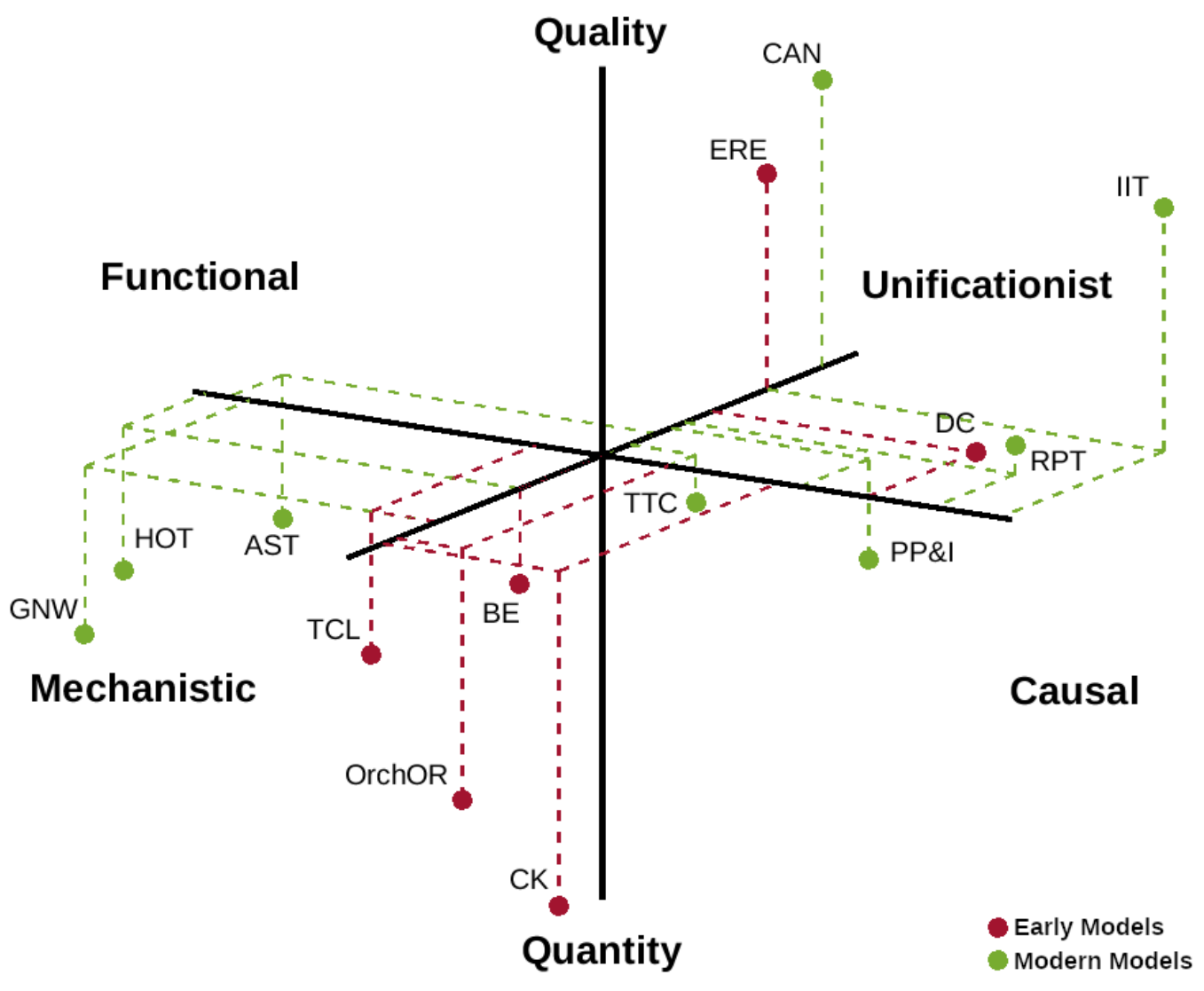

Fig. 2. Classification of the models. Selected models inhabit different explanatory spaces according to our three analytical dimensions. After scanning the literature, summarizing and discussing main tendencies according to the three axis classification in Table 1, each author independently scored models between 1 and $3: 1$ corresponds to a slightly commitment to the direction of the axis and 3 a strong commitment. 0 value was used any time that the model does not qualify for the + or - direction. This quantification is provisional, it only intents to illustrate our framework, and it is not based on statistical data (see details in supplementary section 7). Acronyms stand for Crick and Koch (CK), Dynamical Core (DC), Orchestrated Objective Reduction (OrchOR), Thalamo-Cortical loops and Sensorimotor Couplings (TCL), Beck and Eccles (BE), Enactive and Radical Embodiment (ERE), Global Neuronal Workspace (GNW), Higher-Order Thought Theory (HOT), Recurrent Processing Theory (RPT), Predictive Processing and Interoception (PP\&I), Integrated Information Theory (IIT), Attention Schema Theory (AST), Conscious Agents Networks (CAN), and Temporo-spatial Theory of Consciousness (TTC).

be classified as a causal theory, although different interpretations might exist, e.g. (83).

Additionally, some models seem difficult to classify as either functional or causal in the above sense. For example TTC aims to accommodate both functional and causal types of explanations, making it difficult to identify its commitments (although according to some key quotes it seems to lean towards causal approaches). Other models such as ERE, $\mathrm{CAN}$ and $\mathrm{BE}$ are neither functional nor causal in the sense of (67). This is because they do not share the underlying philosophical assumptions typically made by neuroscientific theories of consciousness (cf. Section 2.1). ERE assumes a form of dynamical co-emergence, i.e. consciousness coarises with the system in such a way that there is a contextual constraint between the biological system (living body) and the experience (lived body), making both interdependent (39). In other words, according to ERE consciousness does not only emerge from the brain and the body, but it also actively constrains them creating a causally reciprocal relationship between neural events and experience (44). Lastly, other non-trivial cases include CAN (consciousness in this case is fundamental and the physical realm is what emerges from it) and BE (which implies a dualist account).

\subsection{Target of explanation}

The final dimension corresponds to the target of explanation, i.e. quality vs quantity of consciousness. We analyzed relevant papers looking for statements revealing what the theory aims to explain. Theories that focus mainly on the contrast between wakefulness and other impaired conditions (TCL) or on what neural activity might underlie the transition from the stimulus being "unseen" to "seen" (GNW, HOT, CK) can be classified as theories of quantity. We encourage the reader to notice that the "why" question posed in case of such theories is not "why a stimulus feels this way", but rather "what constitutes the switch rendering content visible". The stimulus here can be replaced with any other stimulus, as the quality (though not necessarily the structure) of content remains irrelevant and out of the explanatory target. Importantly, answering the first question leads us to "phenomenal content", 
while the second question corresponds to "access content".

An attempt to explain the quality rather than sole quantity is exemplified by IIT. IIT tries to identify the mechanisms behind the phenomenal character of experience, i.e. the quality of its content (what makes an experience visual, auditory, colourful, painful?). In that vein, it poses that the quality of consciousness is in one-to-one correspondence with the geometry, concepts and relations encapsulated by the Maximally Irreducible Conceptual Structures (MICS) (84). IIT predicts that the contents of consciousness are entirely specified by the internal workings of elementary mechanisms of the main complex. Notably though, IIT's agenda to target quality is still in its nascent stages and has not gone beyond trying to explain the spatiality of experience yet (84).

Other models, to a greater or lesser extent, also strive to address quality. One example is ERE. In this theory, first-person reports inform the interpretation of neural signatures, thus co-determining the actual explanandum of the theory (8590). In one particular example, experienced meditators were able to willfully influence neural activity (both short- and long-term) (91). This reveals a more complex relationship between experiential content and its neural substrate: quantitative measures constrain experienced qualities, but quality might in turn constrain quantity (41). Another example, RPT, largely focuses on questions related to phenomenal awareness. There are appreciable ways in which it can explain some qualitative aspects of consciousness, such as the figureground segmentation, i.e. how one might sometimes perceive a texture to be a surface that lies on top of a background (9294). Functional models also claim to target quality, however in a different way, typically using recognition and detection paradigms. For example, HOT, although it tends to delegate "qualities" to largely unspecified mechanisms of low-level representation or the external world, puts forward explanations why we might sometimes feel confident of the perceptual experience (95)).

It is therefore evident that different theories adapt different strategies in addressing the problem of quality depending on their underlying philosophical assumptions. Arguably, these discussions might pave the way for other theories' proponents to appreciate different kinds of explanatory aims and recognize that a mature theory of consciousness should address both the quantity and quality of experience. Novel questions inspired by the focus on quality for theories of quantity could be, inter alia: How exactly does the pattern of global ignition inform phenomenal content? What distinguishes visual or auditory reentrant processing, or in other words, what mechanism makes these two modalities feel differently? Notice that circumventing the problem by referring to the function of the primary sensory cortices (e.g. pre-labelled as visual or auditory) is not tenable, because it does not inform what precisely makes a primary cortex visual or auditory in the first place. Alternatively, for models such as AST, what, on the level of modeling or rerepresenting, specifically correlates with the (illusory) attribution of qualia?

\subsection{Empirical consequences}

The fact that different theories subscribe to different modes, mechanisms, and targets of explanation has several empirical consequences. One of them pertains to the localization of neural correlates of consciousness (NCCs) $(4,8)$. First off, there is a substantial disagreement between the so called first order (e.g. IIT, RPT) and higher order theories (e.g. HOT) insofar that the former typically assign NCCs to the early sensory cortices while the latter to the frontal-parietal network. It is worth pointing out that the "frontal theories" tend to systematically cluster under the mechanistic mode of explanation, often interested in questions of quantity rather than quality (i.e under what conditions a particular stimulus would be classified as consciously perceived or not) (see Figure 2). Notwithstanding these distinctions, most of the models reviewed above are dynamical global network approaches and therefore non-localist in principle (78). The network is relevant, the nodes alone are not. For example, GNW is often misunderstood as a fixed architecture encompassing the fronto-parietal cortices. In actuality, it comprises dynamic neural contributions that define this hypothetical global network (96). The only anatomical constraint is that relevant regions should be connected by long axons of pyramidal neurons. During decades of research, GNW identified pyramidal neurons in layer II and III as candidate mechanisms. In light of recent relevant evidence (97), they have put forward layer $\mathrm{V}$ as a more likely GW substrate (98). On the contrary, IIT postulates that the true NCC lies in the posterior hot zone; one of the main points of contention with GNW being the counterintuitive role of inactive units, contributing to the causeeffect information just as the active ones do $(99,100)$. HOT seems not to specify network mechanisms in sufficiently rigorous details. Even though the original framework has been worked out empirically $(95,101)$, this family of models leave a lot of space to accommodate ambiguous experimental data. Other inconclusive findings include the study of posterior hot zone involvement in dreams $(98,100)$ or PCI index (102). In the first case the reduction of low-frequency activity in posterior zones of the brain correlates with dreams during rapid-eye-movement (REM) sleep and non-REM sleep (100). At the same time, content specific dreams involve highfrequency activity in the frontal and prefrontal cortex. Some authors interpret these results as evidence of posterior zones for phenomenal consciousness and support of IIT, while others view them as clear evidence of the role of prefrontal cortex and GNW (98). In the second case, the PCI index inspired by the IIT framework seems compatible with the global ignitory activity of GNW (98), as well as with other models such as ERE. Another recent study inspired by GNW found that the thalamic nucleus of monkey brains under deep brain stimulation (DBS) restores signatures of consciousness and reactivate nodes of the GNW that remain inactive under anesthesia (103). However, as the authors also pointed out, these results are also compatible with thalamocortical loops theories and IIT.

Therefore, the postulation of either prefrontal regions and posterior regions to be the primary locus of the NCC does 
not by itself speak to different explanatory approaches and probably merely reflects the availability of experimental techniques. Moreover, the question of localization makes sense only if one endorses a mechanistic and causal explanatory framework simultaneously, which is only the case for CK and OrchOR models. If one, by contrast, looks for unification or function, then the fact that, say, frontal or posterior regions are most relevant for the NCC, is contingent. This is particularly true for those views which do not adhere to the explanatory primacy of causal chains within space-time (e.g. CAN). As such, experiments that try to identify the NCC do not provide evidence for or against such a theory. But even within the mechanistic (whether functional or causal) framework, localization approaches are problematic: evidence for some mechanisms at any particular level does not falsify the relevance of other mechanisms at other scales. An interesting example is a controversial recent comparison between IIT and GNW at the single-unit level. At first glance, results suggest that GNW is supported by the evidence, while IIT is not (104). However, considering the active single-unit level as the optimal spatiotemporal scale for testing IIT remains problematic. This would force an assumption of GNW (i.e. that consciousness is correlated to only active neurons) onto IIT, which is prima facie not warranted. But this is a conceptual issue having to do with explanatory commitments - and not an empirical one.

Another empirical consequence of the way a theory emphasizes either quality or quantity has implications for the methodology used. In general, it has been long recognized that the scientific study of consciousness utilizes first-person and third-person approaches (105). The former includes subjective reports and phenomenological interviews (106), the latter refers to objective measures of physical states, using different techniques such as electroencephalography (EEG), functional magnetic resonance imaging (fMRI), magnetoencephalography (MEG), among others. Most models of consciousness claim to employ both subjective and objective accounts. However, their assigned importance varies across the models. In particular, those theories which seek to explain quality will wish to utilize a method that is specifically suited to make the qualitative aspect of experience precise. Particularly promising accounts are called "second-person" methods, referring to interview techniques that incorporate verbal and non-verbal reports in order to obtain a well informed subjective report $(87,89,105)$. This approach is motivated by earlier research in neurophenomenology $(41,85,107)$. The second-person method is different from the first-person method in that the former is guided by an interviewer who reads and interprets various indicators from the first-person subjective report. Given these indicators, the interviewer is able to ask more refined questions that force a subject to closely specify her reports.

Related to the quality versus quantity distinction is the one between levels and contents of consciousness (108-110). Levels of consciousness convey global signatures of consciousness, from which different paradigms contrast awake neural activity against non-awake or disrupted conditions such as sleep, chronic disorders of consciousness, anaesthesia, among others (111). By contrast, paradigms looking for contents of consciousness survey conscious experiences through contrasting perceptual analysis (perceived vs unperceived) and multiple psychophysical reporting paradigms. Examples include masked stimuli, high-contrast figures, binocular rivalry, flash suppression, motion-induced blindness, attentional paradigms, among others (8). However one must not conflate the study of contents with the study of the specific phenomenology of such contents. Yet, approaches that study contents quantitatively might still be understood as studying the structure between instances of (qualitative) consciousness. For example, it has recently been argued that postdictive studies in the auditory domain could uncover the temporal structure of perception (112) - something that has previously been discussed extensively in the phenomenological literature. Thus, in general, it is more appropriate to distinguish between an "access content" and a "phenomenological content", the former allowing an indirect (often dynamical) inference of the structure of consciousness, the latter specifically targeting the "what-it-is-likeness" of experience.

\section{Conclusions: integrative methods for the future}

In light of our previous sections, the empirical testing of models of consciousness is far from trivial. Comparing models of consciousness is not only difficult due to experimental limitations, but also due to the fact that different models operate on very different and mostly implicit assumptions about modes, mechanisms, and targets of explanation. We thus introduced a classification scheme to make the different explanatory profiles of leading models explicit. To our knowledge, this is the first time that all these models and perspectives are reviewed systematically, focusing on different explanatory aspects, analytical dimensions, and organized in one single and comprehensible classification.

Our provisional classification framework serves as an invitation for theorists to weigh in how their own models might be classified. In future attempts, a representative number of experts, performing statistics, and test-retest reliability should be added, among others. One might also speculate that current models of consciousness will change their location in our classification framework, as new versions of them emerge, either in light of new evidence or more refined theoretical discussions.

Having perused the relevant literature around 14 popular frameworks, we suggest that a number of disputes in the field of consciousness studies might stem from differently set explanatory goals and targets. Although both mechanistic and unificationist accounts have their advantages, there are certain areas of research where one of them might turn out to be more suitable than the other. Some types of explanations might require to step back from investigating the specific empirical details and look more at the overall mathematical structure: the reason "why" a person cannot untie a particular knot may stem from a topological fact about the knot, rather than from a detailed causal trajectory illustrating the 
attempt of its disentanglement. Several examples show that a full-fledged explanation of a phenomenon might sometimes require more than a causal story (57). On the other hand, unificationist accounts face their own problems, such as the "problem of asymmetry": if A explains B, B does not explain A. It is heavily contested whether unificationist approaches could accommodate this intuition (65).

It is yet to be established which type of explanation is most adequate for the science of consciousness or whether even different modes of explanation would be required (e.g. manipulationist accounts $(47,49))$. Nonetheless, one of the messages of this paper is to emphasize that the first step towards a more mature science of consciousness is the recognition that the question of why brain activity is correlated to subjective experience can be understood in a variety of ways. We suggest that to fully explain what it means to be conscious, one needs to first be precise about what it would mean to explain something.

Remaining aware of the disagreements within the field (and its early history), one might also try to extract what most models agree on. Some empirical approaches intend to follow this kind of pragmatism. For example, the concept of criticality in dynamical system theory shows to be compatible with both access and phenomenal consciousness signatures (113). The analytical method of connectome harmonics also aims to unify different signatures of consciousness, from a more general perspective of brain functioning and physical system theory (114-116). Large scale models using different anatomical, functional and molecular layers of description also present promising features to integrate different mechanisms at different scales (117), as well as various signatures of consciousness (111). Recently, optogenetic experiments demonstrated that the biophysics of pyramidal neurons in cortical layer V integrates two contentious mechanisms associated with consciousness, i.e. cortico-cortical loops and higher-order thalamocortical loops $(97,118)$. More research aiming at synthesizing different findings is currently underway.

Recent mathematical works too have recognized the need for integration within a sound theoretical foundation. This new trend, "mathematical consciousness science" (119), employs formal and rigorous methods to explore ways to distinguish various models and derive new empirical predictions. Some examples are the mathematical developments, based on IIT $(69,120,121)$ and mathematized phenomenology (122$125)$; other approaches are based on symmetry (126), category theory $(127,128)$ or on the compositionality of processes $(125,129,130)$. Some models explicitly address different metaphysical starting points, such as idealism (36) or decompositional approaches of dual-aspect monism (131). Common to all these approaches is that, inspired by the transparency of mathematics, they explicitly define their core assumptions. In the end, whether they are of any value will be determined by how much explanatory power they bring into the constantly accruing experimental evidence.

The science of consciousness needs integrative frameworks, and integrative frameworks by definition are multidisci- plinary. In the future, and going beyond empirical methods and mathematics, a dialogue with artists, meditators, and proponents of the humanities may help us to think outside the box and rediscover some aspects of conscious experience that have largely been unattended to.

\section{Acknowledgements}

The authors thank Athena Demertzi, Johannes Fahrenfort, Chris Fields, Don Hoffman, Lucia Melloni, Wanja Wiese, and two anonymous referees for helpful comments and constructive feedback. This work received financial support by Comisión Nacional de Investigación Ciencia y Tecnología (CONICYT, currently ANID) through Programa Formacion de Capital Avanzado (PFCHA), Doctoral scholarship Becas Chile: CONICYT PFCHA/DOCTORADO BECAS CHILE/2016 - 72170507, Polish Ministry of Science and Higher Education's Diamond Grant DI2016 020046 and the project Comparative investigation of the cortical circuits in mouse, NHP and human (CORTICITY).

\section{Bibliography}

1. Anil Seth. Models of consciousness. Scholarpedia, 2(1):1328, 2007. ISSN 1941-6016. doi: $10.4249 /$ scholarpedia. 1328 .

2. Anil Seth. Explanatory correlates of consciousness: Theoretical and computational challenges. Cognitive Computation, 1(1):50-63, 2009. ISSN 18669956. doi: 10.1007/ s12559-009-9007-x.

3. Ian Durham, Johannes Kleiner, Yakov Kremnitzer, Jonathan Mason, and Robert Prentner, editors. Models of Consciousness, volume 22. Special is edition, 2020

4. Melanie Boly, Marcello Massimini, Naotsugu Tsuchiya, Bradley R. Postle, Christof Koch, and Giulio Tononi. Are the neural correlates of consciousness in the front or in the back of the cerebral cortex? Clinical and neuroimaging evidence. Journal of Neuroscience, 37 (40):9603-9613, 2017. ISSN 15292401. doi: 10.1523/JNEUROSCI.3218-16.2017.

5. Sara Reardon. Rival theories face off over brain's source of consciousness. Science, 366 (6463):293, 2019. ISSN 10959203. doi: 10.1126/science.366.6463.293.

6. Georg Northoff and Victor Lamme. Neural signs and mechanisms of consciousness: Is there a potential convergence of theories of consciousness in sight? Neuroscience and Biobehavioral Reviews, 118(July):568-587, 2020. ISSN 18737528. doi: 10.1016/j. neubiorev.2020.07.019.

7. Wanja Wiese. The science of consciousness does not need another theory, it needs a minimal unifying model. Neuroscience of Consciousness, 2020(1):1-7, 2020. ISSN 20572107. doi: 10.1093/NC/NIAA013.

8. P. Christiaan Klink, Matthew W. Self, Victor A.F. Lamme, and Pieter R. Roelfsema. Theories and methods in the scientific study of consciousness. In Steven M. Miller, editor, The Constitution of Phenomenal Consciousness. Toward a science and theory., pages 17-47. John Benjamins Publishing Company, 2015. doi: 10.1075/aicr.92.02kli.

9. Ned Block. Comparing the major theories of consciousness. In The cognitive neurosciences, 4th ed., pages 1111-1122. Massachusetts Institute of Technology, Cambridge, MA, US, 2009. ISBN 978-0-262-01341-3 (Hardcover).

10. David M. Rosenthal. How many kinds of consciousness? Consciousness and Cognition, 11(4):653-665, 2002. ISSN 10538100. doi: 10.1016/S1053-8100(02)00017-X.

11. Ned Block. Consciousness, accessibility, and the mesh between psychology and neuroscience. Behavioral and Brain Sciences, 30(5-6):481-548, 2007. ISSN 0140525X. doi: 10.1017/S0140525X07002786.

12. David Rosenthal. Assessing criteria for theories. Cognitive Neuroscience, 00(00):1-2, 2020. ISSN 17588936. doi: 10.1080/17588928.2020.1838471.

13. John R. Searle. How to study consciousness scientifically. Philosophical Transactions of the Royal Society B: Biological Sciences, 353(1377):1935-1942, 1998. ISSN 09628436. doi: 10.1098/rstb.1998.0346.

14. John R. Searle. Consciousness. Annual Review of Neuroscience, 23:557-578, 2000. doi: 10.1146/annurev.neuro.23.1.557.

15. Daniel C. Dennett. Quining Qualia. In A Marcel and E Bisiach, editors, Consciousness in Modern Science. Oxford University Press, 1988.

16. Daniel C. Dennett. Consciousness Explained. Penguin Books Ltd, London, 1991. ISBN 978-0-14-195610-7.

17. Keith Frankish. Illusionism. Imprint Academic, Exeter, 2017.

18. David J. Chalmers. The meta-problem is the problem of consciousness. Journal of Consciousness Studies, 25(9-10):6-61, 2018.

19. Daniel C. Dennett. Facing up to the hard question of consciousness. Philosophical Transactions of the Royal Society B: Biological Sciences, 373(1755), 2018. ISSN 14712970. doi: $10.1098 /$ rstb.2017.0342.

20. Francis Fallon. Dennett on Consciousness: Realism Without the Hysterics. Topoi, 39(1): 35-44, 2020. ISSN 15728749. doi: 10.1007/s11245-017-9502-8.

21. Ned Block. Two neural correlates of consciousness. Trends in Cognitive Sciences, 9(2): 46-52, 2005. ISSN 13646613. doi: 10.1016/j.tics.2004.12.006. 
22. Ned Block. On a confusion about a function of consciousness. Behavioral and Brain Sciences, 18(2):227-247, 1995.

23. Thomas Metzinger. Minimal phenomenal experience. Philosophy and the Mind Sciences, 1(I):7, 2020. doi: 10.33735/phimisci.2020.i.46.

24. Jean Pierre Changeux. The Ferrier Lecture 1998: The molecular biology of consciousness investigated with genetically modified mice. Philosophical Transactions of the Royal Society B: Biological Sciences, 361(1476):2239-2259, 2006. ISSN 09628436. doi: 10.1098/rstb.2006.1832.

25. Lionel Naccache. Why and how access consciousness can account for phenomenal consciousness. Philosophical Transactions of the Royal Society B: Biological Sciences, 373 (1755), 2018. ISSN 14712970. doi: 10.1098/rstb.2017.0357.

26. Peter Fazekas and Morten Overgaard. Perceptual consciousness and cognitive access: An introduction. Philosophical Transactions of the Royal Society B: Biological Sciences, 373(1755), 2018. ISSN 14712970. doi: 10.1098/rstb.2017.0340.

27. David J. Chalmers. Facing Up to the Problem of Consciousness. Journal of Consciousness Studies, (3):200-219, 1995

28. David J. Chalmers. The Conscious Mind. Oxford University Press, 1997. ISBN 9780195117899.

29. Galen Strawson. Realistic monism: Why physicalism entails panpsychism. Journal of Consciousness Studies, 13(10), 2006.

30. David J. Chalmers. Panpsychism and Panprotopsychism. Amherst Lecture in Philosophy, 8, 2013

31. Philip Goff. Galileo's Error: Foundations for a New Science of Consciousness. Phanteon Books, New York, 2019. ISBN 9781524747961.

32. Harald Atmaspacher. 20Th Century Variants of Dual-Aspect Thinking. Mind and Matter, 12(2):245-269, 2014. ISSN 20513003

33. Leopold Stubenberg. Neutral Monism. The Stanford Encyclopedia of Philosophy, 2018.

34. Paul Marshall, Beyond Physicalism, Edward F Kelly, Adam Crabtree, and Paul Marshall Lanham. Transforming the World Into Experience. Journal of Consciousness Studies, 8 (1):59-76, 2001.

35. Donald D. Hoffman. Conscious Realism and the Mind-Body Problem. Mind and Matter, 6 (1):87-121, 2008

36. Donald D. Hoffman and Chetan Prakash. Objects of consciousness. Frontiers in Psychology, 5(JUN):1-22, 2014. ISSN 16641078. doi: 10.3389/fpsyg.2014.00577.

37. Bernardo Kastrup. An Ontological Solution to the Mind-Body Problem. Philosophies, 2(4): 10, 2017. ISSN 2409-9287. doi: 10.3390/philosophies2020010.

38. David J Chalmers. Idealism and the Mind-Body Problem. In William Seager, editor, The Routledge Handbook of Panpsychism., pages 353-373. Routledge, New York, 2019.

39. Evan Thompson. Mind in Life. Harvard University Press, 2007. ISBN 978-0-674-02511-0.

40. Eugenio Rodríguez. Ideas para naturalizar el estudio de la conciencia. In Edmundo Kronmüller and Carlos Cornejo, editors, Ciencias de la mente: aproximaciones desde Latinoamerica, pages 301-324. Juan Carlos Sáez Editor, 2008. ISBN 9789563060348.

41. Francisco J Varela. Neurophenomenology: A Methodological Remedy for the Hard Problem. Journal of Consciousness Studies, 3(4):330-349, 1996. ISSN 13558250.

42. Shaun Gallagher and Dan Zahavi. The phenomenological mind. Routledge, London, first edition, 2008. ISBN 0203086597. doi: 10.5860/choice.50- 1996.

43. Stephan Kaufer and Anthony Chemero. Phenomenology: An Introduction. Polity, New York, 2015. ISBN 978-0-745-65147-7.

44. Evan Thompson and Francisco Varela. Radical embodiment: neural dynamics and consciousness. Trends in cognitive sciences, 5(October):418-425, 2001. ISSN 03663175.

45. Ernest Nagel. The Structure of Science: Problems in the Logic of Scientific Explanation. Harcourt, New York, 1961. doi: 10.2307/2183206.

46. Wesley C. Salmon. Scientific Explanation: Causation and Unification. Crítica (México $D$. F. En línea), 22(66):3-23, 1990. ISSN 0011-1503. doi: 10.22201/iifs.18704905e.1990.773.

47. James Woodward. Scientific Explanation. The Stanford Encyclopedia of Philosophy, 2019.

48. James Woodward. II-James Woodward: Mechanistic Explanation: Its Scope and Limits. Aristotelian Society Supplementary Volume, 87(1):39-65, 2013. ISSN 0309-7013. doi: 10.1111/j.1467-8349.2013.00219.x.

49. James Woodward. Making Things Happen. Oxford University Press, jan 2004. ISBN 9780195155273. doi: 10.1093/0195155270.001.0001

50. Michael Strevens. The causal and unification approaches to explanation unified - Causally Nous, 38(1):154-176, 2004. ISSN 00294624. doi: 10.1111/j.1468-0068.2004.00466.x.

51. Matteo Colombo. Why build a virtual brain ? Large-scale neural simulations as jump start for cognitive computing. Journal of Experimental \& Theoretical Artificial Intelligence, 3079 (February):1-10, 2017. ISSN 0952-813X. doi: 10.1080/0952813X.2016.1148076.

52. Henk W. de Regt and Christoph Baumberger. What Is Scientific Understanding and How Can It Be Achieved? What Is Scientific Knowledge?, pages 66-81, 2019. doi: 10.4324/ 9780203703809-5.

53. Robert Van Gulick. Consciousness. The Stanford Encyclopedia of Philosophy, 2018.

54. Colin McGinn. Consciousness and content. In Proceedings of the British Academy, volume 74, pages 219-239. 1988.

55. DJ Chalmers. The puzzle of conscious experience. Scientific American, 273(6):80-86, 1995.

56. Jakob Hohwy and Chris Frith. Can neuroscience explain consciousness? Journal of Consciousness Studies, 11(7-8):180-198, 2004. ISSN 13558250.

57. Alexander Reutlinger. Explanation beyond causation? New directions in the philosophy of scientific explanation. Philosophy Compass, 12(2):1-11, 2017. ISSN 17479991. doi: $10.1111 /$ phc3.12395.

58. Marco J. Nathan. Causation vs. Causal Explanation: Which Is More Fundamental? Foundations of Science, (0123456789), 2020. ISSN 15728471. doi: $10.1007 /$ s10699-020-09672-2.

59. Carl F. Craver. Explaining the brain: Mechanisms and the mosaic unity of neuroscience. Oxford University Press. Oxford University Press, 2007. ISBN 9780199299317.

60. Clark Glymour. Explanations, Tests, Unity, and Necessity. Nous, 14:31-50, 1980.

61. Philip Kitcher. Explanatory Unification. Philosophy of Science, 48(4):507-531, dec 1981. ISSN 0031-8248. doi: 10.1086/289019.
62. Robert W. Batterman and Collin C. Rice. Minimal model explanations. Philosophy of Science, 81(3):349-376, 2014. ISSN 00318248. doi: 10.1086/676677.

63. Michael L. Anderson and Tony Chemero. The problem with brain GUTs: Conflation of different senses of "prediction" threatens metaphysical disaster. Behavioral and Brain Sciences, 36(3):204-205, jun 2013. ISSN 0140-525X. doi: 10.1017/S0140525X1200221X.

64. Tim Bayne. On the axiomatic foundations of the integrated information theory of consciousness. Neuroscience of Consciousness, 2018(1):1-8, 2018. ISSN 2057-2107. doi: 10.1093/nc/niy007.

65. Eric Barnes. Explanatory Unification and the Problem of Asymmetry. Philosophy of Science, 59(4):558-571, 1992. ISSN 0031-8248. doi: 10.1086/289695.

66. Phyllis Mc Kay Illari and Jon Williamson. What is a mechanism? Thinking about mechanisms across the sciences. European Journal for Philosophy of Science, 2(1):119-135, 2012. ISSN 18794920. doi: 10.1007/s13194-011-0038-2.

67. Adrien Doerig, Aaron Schurger, Kathryn Hess, and Michael H. Herzog. The unfolding argument: Why IIT and other causal structure theories cannot explain consciousness. Consciousness and Cognition, 72(November 2018):49-59, 2019. ISSN 10902376. doi: 10.1016/j.concog.2019.04.002.

68. Ned Block. What is functionalism? In The Encyclopedia of Philosophy Supplement. 1996.

69. Naotsugu Tsuchiya, Shigeru Taguchi, and Hayato Saigo. Using category theory to assess the relationship between consciousness and integrated information theory. Neuroscience Research, 107:1-7, 2016. ISSN 18728111. doi: 10.1016/j.neures.2015.12.007.

70. Terence E Horgan, John L Tienson, and George Graham. Phenomenal intentionality and the brain in a vat. In Richard Schantz, editor, The Externalist Challenge. De Gruyter, 2004.

71. Sydney Shoemaker. Phenomenal Character Revisited. Philosophy and Phenomenological Research, 60(2):465, 2000. ISSN 00318205. doi: 10.2307/2653497.

72. Ned Block. Sexism, Racism, Ageism, and the Nature of Consciousness. Philosophical Topics, 26(1):39-70, 1999. ISSN 0276-2080. doi: 10.5840/philtopics1999261/233.

73. Adam Pautz. The Real Trouble with Phenomenal Externalism: New Empirical Evidence for a Brain-Based Theory of Consciousness. In Richard Brown, editor, Consciousness Inside and Out: Phenomenology, Neuroscience, and the Nature of Experience, pages 237-317. Springer, Dordrecht, 2014. doi: 10.1007/978-94-007-6001-118.

74. Tim Bayne and Olivia Carter. Dimensions of consciousness and the psychedelic state. Neuroscience of Consciousness, 4(1):1-8, 2018. doi: 10.1093/nc/niy008.

75. Chetan Prakash, Chris Fields, Donald D. Hoffman, Robert Prentner, and Manish Singh. Fact, fiction, and fitness. Entropy, 22(5):1-23, 2020. ISSN 10994300. doi: 10.3390/ E22050514.

76. Michael S. A. Graziano, Arvid Guterstam, Branden J. Bio, and Andrew I. Wilterson. Toward a standard model of consciousness: Reconciling the attention schema, global workspace, higher-order thought, and illusionist theories. Cognitive Neuropsychology, 37(3-4):155172, may 2020. ISSN 0264-3294. doi: 10.1080/02643294.2019.1670630.

77. David M Rosenthal. Consciousness and its function. Neuropsychologia, 46(3):829-840, jan 2008. ISSN 00283932. doi: 10.1016/j.neuropsychologia.2007.11.012.

78. Stanislas Dehaene and Lionel Naccache. Towards a cognitive neuroscience of conscious ness: Basic evidence and a workspace framework. Cognition, 79(1-2):1-37, 2001. ISSN 00100277. doi: 10.1016/S0010-0277(00)00123-2.

79. Wanja Wiese and Karl J Friston. The neural correlates of consciousness under the free energy principle: From computational correlates to computational explanation. Philosophy and the Mind Sciences, forthcomin, 2021. doi: 10.31234/osf.io/7gefk.

80. Chris Fields, Donald D. Hoffman, Chetan Prakash, and Manish Singh. Conscious agent networks: Formal analysis and application to cognition. Cognitive Systems Research, 47 (October):186-213, 2018. ISSN 13890417. doi: 10.1016/j.cogsys.2017.10.003.

81. Matthias Michel, Diane Beck, Ned Block, Hal Blumenfeld, Richard Brown, David Carmel, Marisa Carrasco, Mazviita Chirimuuta, Marvin Chun, Axel Cleeremans, Stanislas De haene, Stephen M. Fleming, Chris Frith, Patrick Haggard, Biyu J. He, Cecilia Heyes, Melvyn A. Goodale, Liz Irvine, Mitsuo Kawato, Robert Kentridge, Jean Remi King, Robert T. Knight, Sid Kouider, Victor Lamme, Dominique Lamy, Hakwan Lau, Steven Laureys, Joseph LeDoux, Ying Tung Lin, Kayuet Liu, Stephen L. Macknik, Susana MartinezConde, George A. Mashour, Lucia Melloni, Lisa Miracchi, Myrto Mylopoulos, Lionel Naccache, Adrian M. Owen, Richard E. Passingham, Luiz Pessoa, Megan A.K. Peters, Dobromir Rahnev, Tony Ro, David Rosenthal, Yuka Sasaki, Claire Sergent, Guillermo Solovey, Nicholas D. Schiff, Anil Seth, Catherine Tallon-Baudry, Marco Tamietto, Frank Tong, Simon van Gaal, Alexandra Vlassova, Takeo Watanabe, Josh Weisberg, Karen Yan, and Masatoshi Yoshida. Opportunities and challenges for a maturing science of consciousness. Nature Human Behaviour, 3(2):104-107, 2019. ISSN 23973374. doi: 10.1038/s41562-019-0531-8.

82. Johannes J. Fahrenfort and Simon van Gaal. Criteria for empirical theories of consciousness should focus on the explanatory power of mechanisms, not on functional equivalence. Cognitive Neuroscience, 12(2):93-94, apr 2021. ISSN 1758-8928. doi: 10.1080/17588928.2020.1838470.

83. Andy Clark. Surfing Uncertainity. Prediction, Action, and the Embodied Mind. Oxford University Press, Oxford, jan 2016. ISBN 9780190217013. doi: 10.1093/acprof: oso/9780190217013.001.0001.

84. Andrew Haun and Giulio Tononi. Why does space feel theway it does? Towards a principled account of spatial experience. Entropy, 21(12), 2019. ISSN 10994300. doi: 10.3390/e21121160.

85. Antoine Lutz, Jean Philippe Lachaux, Jacques Martinerie, and Francisco J. Varela. Guiding the study of brain dynamics by using first-person data: Synchrony patterns correlate with ongoing conscious states during a simple visual task. Proceedings of the National Academy of Sciences of the United States of America, 99(3):1586-1591, 2002. ISSN 00278424. doi: 10.1073/pnas.032658199.

86. Antoine Lutz and Evan Thompson. Neurophenomenology: Integrating Subjective Experience and Brain Dynamics in the Neuroscience of Consciousness. Journal of Consciousness Studies, 10(9-10):31-52, 2003. ISSN 13558250.

87. Antoine Lutz, Amishi P. Jha, John D. Dunne, and Clifford D. Saron. Investigating the phenomenological matrix of mindfulness-related practices from a neurocognitive perspective. American Psychologist, 70(7):632-658, oct 2015. ISSN 1935-990X. doi: 
10.1037/a0039585.

88. Jennifer M. Windt, Tore Nielsen, and Evan Thompson. Does Consciousness Disappear in Dreamless Sleep? Trends in Cognitive Sciences, 20(12):871-882, 2016. ISSN 1879307X. doi: 10.1016/j.tics.2016.09.006.

89. Claire Petitmengin, Anne Remillieux, and Camila Valenzuela-Moguillansky. Discovering the structures of lived experience. Phenomenology and the Cognitive Sciences, 18(4): 691-730, sep 2019. ISSN 1568-7759. doi: 10.1007/s11097-018-9597-4.

90. S. Poletti, O. Abdoun, J. Zorn, and A. Lutz. Pain regulation during mindfulness meditation: phenomenological fingerprints in novices and experts practitioners. European Journal of Pain, (March), 2021. ISSN 1090-3801. doi: 10.1002/ejp.1774.

91. A Lutz, LL Greischar, NB Rawlings, M Ricard, and R Davidson. Long-term meditators self-induce high-amplitude gamma synchrony during mental practice. Proceedings of the National Academy of Sciences, 101(46):16369-16373, 2004.

92. Pieter R. Roelfsema, Victor A.F. Lamme, Henk Spekreijse, and Holger Bosch. Figure - Ground segregation in a recurrent network architecture. Journal of Cognitive Neuro science, 14(4):525-537, 2002. ISSN 0898929X. doi: 10.1162/08989290260045756.

93. H. Steven Scholte, Jacob Jolij, Johannes J. Fahrenfort, and Victor A.F. Lamme. Feedforward and recurrent processing in scene segmentation: Electroencephalography and functional magnetic resonance imaging. Journal of Cognitive Neuroscience, 20(11):20972109 , 2008. ISSN 0898929X. doi: $10.1162 /$ jocn.2008.20142.

94. Johannes J. Fahrenfort, Jonathan Van Leeuwen, Christian N.L. Olivers, and Hinze Hogendoorn. Perceptual integration without conscious access. Proceedings of the National Academy of Sciences of the United States of America, 114(14):3744-3749, 2017. ISSN 10916490. doi: 10.1073/pnas.1617268114.

95. Richard Brown, Hakwan Lau, and Joseph E. LeDoux. Understanding the Higher-Order Approach to Consciousness. Trends in Cognitive Sciences, 23(9):754-768, 2019. ISSN 1879307X. doi: 10.1016/j.tics.2019.06.009.

96. Stanislas Dehaene and Jean Pierre Changeux. Ongoing spontaneous activity controls access to consciousness: A neuronal model for inattentional blindness. PLoS Biology, 3 (5):0910-0927, 2005. ISSN 15457885. doi: 10.1371/journal.pbio.0030141.

97. Mototaka Suzuki and Matthew E. Larkum. General Anesthesia Decouples Cortical Pyramidal Neurons. Cell, 180(4):666-676.e13, 2020. ISSN 10974172. doi: 10.1016/j.cell.2020. 01.024 .

98. George A. Mashour, Pieter Roelfsema, Jean Pierre Changeux, and Stanislas Dehaene. Conscious Processing and the Global Neuronal Workspace Hypothesis. Neuron, 105(5): 776-798, 2020. ISSN 10974199. doi: 10.1016/j.neuron.2020.01.026.

99. Masafumi Oizumi, Larissa Albantakis, and Giulio Tononi. From the phenomenology to the mechanisms of consciousness: Integrated Information Theory 3.0. PLoS computational biology, 10(5):e1003588, may 2014. ISSN 1553-7358. doi: 10.1371/journal.pcbi.1003588.

100. Francesca Siclari, Benjamin Baird, Lampros Perogamvros, Giulio Bernardi, Joshua J LaRocque, Brady Riedner, Melanie Boly, Bradley R Postle, and Giulio Tononi. The neural correlates of dreaming. Nature Neuroscience, 20(6):872-878, 2017. ISSN 1097-6256. doi: $10.1038 / \mathrm{nn} .4545$

101. Hakwan C. Lau and Richard E. Passingham. Relative blindsight in normal observers and the neural correlate of visual consciousness. Proceedings of the National Academy of Sciences of the United States of America, 103(49):18763-18768, 2006. ISSN 00278424. doi: 10.1073/pnas.0607716103.

102. Silvia Casarotto, Angela Comanducci, Mario Rosanova, Simone Sarasso, Matteo Fecchio, Martino Napolitani, Andrea Pigorini, Adenauer G. Casali, Pietro D. Trimarchi, Melanie Boly, Olivia Gosseries, Olivier Bodart, Francesco Curto, Cristina Landi, Maurizio Mariotti, Guya Devalle, Steven Laureys, Giulio Tononi, and Marcello Massimini. Stratification of unresponsive patients by an independently validated index of brain complexity. Annals of Neurology, 80(5):718-729, 2016. ISSN 15318249. doi: 10.1002/ana.24779.

103. Jordy Tasserie. Functional neuro-imaging study of Deep Brain Stimulation mechanisms for the restoration of consciousness using a Non-Human Primate model. PhD thesis, 2020.

104. Jean Paul Noel, Yumiko Ishizawa, Shaun R. Patel, Emad N. Eskandar, and Mark T. Wallace. Leveraging Nonhuman Primate Multisensory Neurons and Circuits in Assessing Consciousness Theory. The Journal of neuroscience : the official journal of the Society for Neuroscience, 39(38):7485-7500, 2019. ISSN 15292401. doi: 10.1523/JNEUROSCI. 0934-19.2019.

105. Francisco A. Olivares, Esteban Vargas, Claudio Fuentes, David Martínez-Pernía, and Andrés Canales-Johnson. Neurophenomenology revisited: Second-person methods for the study of human consciousness. Frontiers in Psychology, 6(May):1-12, 2015. ISSN 16641078. doi: $10.3389 /$ fpsyg.2015.00673.

106. DJ Chalmers. How can we construct a science of consciousness? Annals of the New York Academy of Sciences, 1303(1):25-35, 2013. doi: 10.1111/nyas.12166.

107. Evan Thompson. Life and mind: From autopoiesis to neurophenomenology. A tribute to Francisco Varela. Phenomenology and the Cognitive Sciences, 3(4):381-398, 2004. ISSN 1568-7759. doi: 10.1023/b:phen.0000048936.73339.dd.

108. Talis Bachmann and Anthony G. Hudetz. It is time to combine the two main traditions in the research on the neural correlates of consciousness: $\mathrm{C}=\mathrm{LxD}$. Frontiers in Psychology, 5(AUG):1-13, 2014. ISSN 16641078. doi: 10.3389/fpsyg.2014.00940.

109. Tim Bayne, Jakob Hohwy, and Adrian M. Owen. Are There Levels of Consciousness? Trends in Cognitive Sciences, 20(6):405-413, 2016. ISSN 1879307X. doi: 10.1016/j.tics. 2016.03.009.

110. Johan F. Storm, Mélanie Boly, Adenauer G. Casali, Marcello Massimini, Umberto Olcese, Cyriel M.A. Pennartz, and Melanie Wilke. Consciousness Regained: Disentangling Mechanisms, Brain Systems, and Behavioral Responses. The Journal of Neuroscience, 37(45) 10882-10893, 2017. ISSN 0270-6474. doi: 10.1523/jneurosci.1838-17.2017.

111. Camilo Miguel Signorelli, Joaquin Diaz Boils, Enzo Tagliazucchi, Bechir Jarraya, and Gustavo Deco. From brain-body function to consciousness interaction. (under review), 2021.

112. Michael H. Herzog, Leila Drissi-Daoudi, and Adrien Doerig. All in Good Time: LongLasting Postdictive Effects Reveal Discrete Perception. Trends in Cognitive Sciences, 24 (10):826-837, 2020. ISSN 1879307X. doi: 10.1016/j.tics.2020.07.001.

113. Enzo Tagliazucchi. The signatures of conscious access and its phenomenology are consistent with large-scale brain communication at criticality. Consciousness and Cognition,
55(August):136-147, 2017. ISSN 10902376. doi: 10.1016/j.concog.2017.08.008.

114. Selen Atasoy, Gustavo Deco, Morten L. Kringelbach, and Joel Pearson. Harmonic Brain Modes: A Unifying Framework for Linking Space and Time in Brain Dynamics. The Neuroscientist, page 107385841772803, 2017. ISSN 1073-8584. doi: 10.1177/ 1073858417728032.

115. Selen Atasoy, Gustavo Deco, and Morten L. Kringelbach. Playing at the Edge of Criticality: Expanded Whole-Brain Repertoire of Connectome-Harmonics. In N. Tomen, editor, The Functional Role of Critical Dynamics in Neural Systems, volume 11, pages 2745. Springer International Publishing, 2019. ISBN 978-3-030-20964-3. doi: 10.1007/ 978-3-030-20965-0_2

116. A I Luppi, J Vohryzek, P A M Mediano, R Adapa, I Pappas, P Finoia, J Allanson, S Atasoy, and $\mathrm{E}$ A Stamatakis. Connectome Harmonic Decomposition of Human Brain Dynamics Reveals a Landscape of Consciousness. bioRxiv, 2020. doi: 10.1101/2020.08.10.244459.

117. Morten L. Kringelbach, Josephine Cruzat, Joana Cabral, Gitte Moos Knudsen, Robin Carhart-Harris, Peter C. Whybrow, Nikos K. Logothetis, and Gustavo Deco. Dynamic coupling of whole-brain neuronal and neurotransmitter systems. Proceedings of the National Academy of Sciences of the United States of America, 117(17):9566-9576, 2020. ISSN 10916490. doi: 10.1073/pnas.1921475117.

118. Jaan Aru, Mototaka Suzuki, and Matthew E. Larkum. Cellular Mechanisms of Conscious Processing. Trends in Cognitive Sciences, 24(10):814-825, 2020. ISSN 1879307X. doi: 10.1016/j.tics.2020.07.006

119. Association for Mathematical Consciousness Science (AMCS). https://amcscommunity.org, 2021.

120. Masafumi Oizumi, Naotsugu Tsuchiya, and Shun Ichi Amari. Unified framework for information integration based on information geometry. Proceedings of the National Academy of Sciences of the United States of America, 113(51):14817-14822, 2016. ISSN 10916490. doi: 10.1073/pnas.1603583113.

121. Johannes Kleiner and Sean Tull. The mathematical structure of integrated information theory. arXiv, pages 1-22, 2020. ISSN 23318422

122. Jeffrey Yoshimi. Mathematizing phenomenology. Phenomenology and the Cognitive Sciences, 6(3):271-291, 2007. ISSN 15687759. doi: 10.1007/s11097-007-9052-4.

123. Andrée C. Ehresmann and Jaime Gomez-Ramirez. Conciliating neuroscience and phenomenology via category theory. Progress in Biophysics and Molecular Biology, 119(3): 347-359, 2015. ISSN 00796107. doi: 10.1016/j.pbiomolbio.2015.07.004.

124. Robert Prentner. Consciousness and topologically structured phenomenal spaces. Consciousness and Cognition, 70(February):25-38, 2019. ISSN 10902376. doi: 10.1016/j. concog.2019.02.002.

125. Camilo Miguel Signorelli, Quanlong Wang, and Bob Coecke. Reasoning about conscious experience with axiomatic and graphical mathematics. Consciousness and Cognition, 2021

126. Johannes Kleiner. Mathematical Models of Consciousness. Entropy, 22(6):609, may 2020 ISSN 1099-4300. doi: 10.3390/e22060609.

127. Georg Northoff, Naotsugu Tsuchiya, and Hayato Saigo. Mathematics and the Brain: A Category Theoretical Approach to Go Beyond the Neural Correlates of Consciousness. Entropy, 21(12):1234, dec 2019. ISSN 1099-4300. doi: 10.3390/e21121234.

128. Naotsugu Tsuchiya and Hayato Saigo. Applying Yoneda's lemma to consciousness research: categories of level and contents of consciousness. Preprint, 2020. doi: 10.31219/osf.io/68nhy.

129. Camilo Miguel Signorelli and Daniel Meling. Towards new concepts for a biological neuroscience of consciousness. Cognitive Neurodynamics, jan 2021. ISSN 1871-4080. doi: 10.1007/s11571-020-09658-7.

130. Camilo Miguel Signorelli, Quanlong Wang, and llyas Khan. A Compositional Model of Consciousness Based on Consciousness-Only. Entropy, 23(3):308, mar 2021. ISSN 10994300. doi: 10.3390/e23030308.

131. Harald Atmanspacher. The Pauli-Jung Conjecture and Its Relatives: A Formally Augmented Outline. Open Philosophy, 3(1):527-549, sep 2020. ISSN 2543-8875. doi: 10.1515/opphil-2020-0138.

132. Francis Crick and Christof Koch. Consciousness and neuroscience. Cerebral cortex, 8: 97-1007, 1998. doi: 10.1093/cercor/8.2.97.

133. Gerald M Edelman. Naturalizing consciousness: A theoretical framework. Proceedings of the National Academy of Sciences, 100(9):5520-5524, apr 2003. ISSN 0027-8424. doi: 10.1073/pnas.0931349100.

134. Rodolfo Llinás. Consciousness and the thalamocortical loop. International Congress Series, 1250(C):409-416, 2003. ISSN 05315131. doi: 10.1016/S0531-5131(03)01067-7.

135. R Llinas, U Ribary, D. Contreras, and C. Pedroarena. The neuronal basis for consciousness. Philosophical Transactions of the Royal Society of London B, 353:1841-1849, 1998.

136. Friedrich Beck and J. C. Eccles. Quantum aspects of brain activity and the role of consciousness. Proceedings of the National Academy of Sciences, 89(23):11357-11361, 1992. ISSN 0027-8424. doi: $10.1073 /$ pnas.89.23.11357.

137. SR Hameroff and Roger Penrose. Consciousness in the universe: A review of the "Orch OR" theory. Physics of Life Reviews, 11:39-78, 2014. ISSN 00314749. doi: 10.1016/j. plrev.2013.08.002

138. Michael S.A. Graziano and Sabine Kastner. Human consciousness and its relationship to social neuroscience: A novel hypothesis. Cognitive Neuroscience, 2(2):98-113, 2011. ISSN 17588928. doi: 10.1080/17588928.2011.565121.

139. Giulio Tononi, Melanie Boly, Marcello Massimini, and Christof Koch. Integrated information theory: from consciousness to its physical substrate. Nature reviews. Neuroscience, 17 (7):450-61, jul 2016. ISSN 1471-0048. doi: 10.1038/nrn.2016.44.

140. Victor A.F. Lamme. How neuroscience will change our view on consciousness. Cognitive Neuroscience, 1(3):204-220, 2010. ISSN 17588928. doi: 10.1080/17588921003731586.

141. Georg Northoff and Zirui Huang. How do the brain's time and space mediate consciousness and its different dimensions? Temporo-spatial theory of consciousness (TTC). Neuroscience and Biobehavioral Reviews, 80(May):630-645, 2017. ISSN 18737528. doi: 10.1016/j.neubiorev.2017.07.013.

142. Francis Crick and Christof Koch. A Framework for Consciousness. Nature neuroscience, 6(2):119-126, 2003 
143. David M. Rosenthal. Explaining consciousness. In Philosophy of mind: Classical and contemporary readings., pages 406-421. 2002.

144. Taylor W. Webb and Michael S.A. Graziano. The attention schema theory: A mechanistic account of subjective awareness. Frontiers in Psychology, 6(APR):1-11, 2015. ISSN 16641078. doi: 10.3389/fpsyg.2015.00500.

145. Bernard J Baars. Global workspace theory of consciousness: toward a cognitive neuroscience of human experience. Progress in brain research, 150:45-53, jan 2005. ISSN 0079-6123. doi: 10.1016/S0079-6123(05)50004-9.

146. Victor A.F. Lamme. Why visual attention and awareness are different, 2003. ISSN 13646613.

147. Karl J. Friston, Wanja Wiese, and J. Allan Hobson. Sentience and the origins of consciousness: From cartesian duality to Markovian monism. Entropy, 22(5):1-31, 2020 ISSN 10994300. doi: 10.3390/E22050516. 


\section{Supplementary: Relevant Citations}

Table 2. Mode of explanations. Mechanistic versus Unification.

\begin{tabular}{|c|c|c|}
\hline Model & Quotes & Classification \\
\hline$\overline{\overline{\mathrm{CK}}}$ & $\begin{array}{l}\text { "...all the different aspects of consciousness (pain, visual awareness, self- } \\
\text { consciousness, and so on) employ a basic common mechanism or perhaps a few such } \\
\text { mechanisms" (132) }\end{array}$ & $\overline{\mathrm{Me}}$ \\
\hline$\overline{\mathrm{DC}}$ & $\begin{array}{l}\text { "It allows us to pay attention to the hard enough problem, which is to formulate } \\
\text { a global theory that provides neural bases for the general and special features of } \\
\text { consciousness"(133) }\end{array}$ & Unificationi \\
\hline TCL & $\begin{array}{l}\text { "... the assumption that the intrinsic electrical properties of neurons, and the dynamic } \\
\text { events resulting from their connectivity, result in global resonant states, which we } \\
\text { know as cognition [and consciousness]" (134) "we may conclude that consciousness } \\
\text { is a noncontinuous event determined by synchronous activity in the thalamocortical } \\
\text { system" (134) "We propose...that consciousness, like locomotion, might be more a } \\
\text { case of intrinsic activity than of sensory drive" (135) }\end{array}$ & Mechanistic \\
\hline ERE & $\begin{array}{l}\text { "We also propose that the processes crucial for consciousness cut across the } \\
\text { brain-body-world divisions rather than being located simply in the head" ( } 44)\end{array}$ & Unif \\
\hline$\overline{\mathrm{BE}}$ & $\begin{array}{l}\text { "Combining these observations with our quantum mechan- ical analysis of bouton } \\
\text { exocytosis, we present now the hypothesis that the mental intention (the volition) be- } \\
\text { comes neurally effective by momentarily increasing the probability of exocytosis in } \\
\text { selected cortical areas such as the SMA neurons" (136) }\end{array}$ & Mech \\
\hline OrchOR & $\begin{array}{l}\text { "It is to be expected that the actual mechanisms underlying the production of con- } \\
\text { sciousness in a human brain will be very much more sophisticated than any that we } \\
\text { can put forward at the present time, and would be likely to differ in many important } \\
\text { respects from any that we would be in a position to anticipate in our current propos- } \\
\text { als. Nevertheless, we do feel that the suggestions that we are putting forward here } \\
\text { represent a serious attempt to grapple with the fundamental issues raised by the con- } \\
\text { sciousness phenomenon, and it is in this spirit that we present them here." (137) }\end{array}$ & Mecl \\
\hline HOT & $\begin{array}{l}\text { "It is widely accepted that we understand something only when we can explain it, } \\
\text { and explaining a natural phenomenon typically if not always means locating it in its } \\
\text { distinctive causal nexus." (77) }\end{array}$ & $\mathrm{Mec}$ \\
\hline AST & $\begin{array}{l}\text { "We find a deep commonality between HOT, GW, AST, and the illusionist approach } \\
\text { to consciousness. Here we suggest that these theories can be understood as different, } \\
\text { interlocking perspectives on the same underlying mechanism." (76), "What exactly } \\
\text { is the inner essence, the feeling of consciousness, that seems to be attached to the } \\
\text { information?... Here we propose that the machinery for social perception provides } \\
\text { that feeling of consciousness"(138) }\end{array}$ & Unification \\
\hline IIT & $\begin{array}{l}\text { "IIT provides a principled explanation for several seemingly disparate facts about the } \\
\text { PSC. (...) why is consciousness generated by the corticothalamic system - or at least } \\
\text { some parts of it, but not by the cerebellum, despite the latter having even more neu- } \\
\text { rons? Why does consciousness fade early in sleep, although the brain remains active? } \\
\text { Why is it lost during generalized seizures, when neural activity is intense and syn- } \\
\text { chronous? And why is there no direct contribution to consciousness from neural ac- } \\
\text { tivity within sensory and motor pathways, or within neural circuits looping out of the } \\
\text { cortex into subcortical structures and back, despite their manifest ability to influence } \\
\text { the content of experience? Explaining these facts in a parsimonious manner calls for } \\
\text { a theory of consciousness." (139) }\end{array}$ & Unificationis \\
\hline$\overline{\text { GNW }}$ & $\begin{array}{l}\text { "tools of cognitive psychology and neuroscience may suffice to analyze conscious- } \\
\text { ness. (...) Our view, however, is that conscious access is one of the few empirically } \\
\text { tractable problems presently accessible to an authentic scientific investigation. We } \\
\text { further hope that an understanding of the neural processes that lead to overt report } \\
\text { will eventually result in a theory of covert acts of self- report, and thus may ultimately } \\
\text { contribute to an explanation of the nature of our private phenomenal world." (78) }\end{array}$ & $\mathrm{Mec}$ \\
\hline
\end{tabular}


RPT "That is the point of view of a science that goes beyond neural correlates of things

Unificationist we believe to exist introspectively or behaviorally. In this account, neuroscience is used to produce explanatory correlates (Seth, 2009) to arrive at a framework with maximal explanatory power regarding consciousness and its relation to other cognitive functions ... Here, the behavioral and neural data are taken together to arrive at concepts that are better than the ones that can be arrived at by either psychology or neuroscience independently." (140)

PPI "Even if a measure based on information length should turn out to be equivalent to existing measures of dynamical complexity, it would be advantageous, because it could unify existing approaches under a single overarching principle (i.e., the FEP). (...) Minimising variational free energy could count as a minimal unifying model: variational free energy must be minimised by every self-organising system that persists, and hence also by any conscious system." (79)

TTC "While these views [other current models] presuppose and implicitly touch upon the brain's own time and space, they do not consider time and space themselves central dimensions of the brain's neural activity in an explicit way, that is, how the brain itself constructs time and space in its neural activity" (141) "The main and overarching aim of this review is to provide a unified hypothesis that directly links and thus integrates the different forms of neural activity with the different dimensions of consciousness" (141) "The TTC is primarily a neuroscientific theory of brain and consciousness, which may carry major philosophical implications in terms of a novel view of consciousness, and a paradigm shift from mind-body problem to world-brain problem" (141)

CAN "classical notion of an observer-independent "objective" reality comprising spatiallybounded, time-persistent "ordinary objects" and well-defined local causal processes must simply be abandoned (...) if we want to go beyond this "applied science" and understand the true nature of the mind and the reality beyond it, we can't look to neurons or brains..." (80) 
Table 3. Mechanism of explanations. Functional versus Causal.

\begin{tabular}{|c|c|c|}
\hline Model & Quotes & Classification \\
\hline $\mathrm{CK}$ & $\begin{array}{l}\text { "A node, all by itself, cannot produce consciousness. Even if the neurons in that } \\
\text { node were firing appropriately, this would produce little effect if their output synapses } \\
\text { were inactivated. A node is a node, not a network. Thus a particular coalition is } \\
\text { an active network, consisting of the relevant set of interacting nodes that temporarily } \\
\text { sustains itself. (...) What could be special about this activity that reaches above the } \\
\text { consciousness threshold? It might be some particular way of firing, such as a sustained } \\
\text { high rate, some sort of synchronized firing or firing in bursts. Or it might be the firing } \\
\text { of special types of neurons, such as those pyramidal cells that project to the front of } \\
\text { the brain" (142). }\end{array}$ & Causal \\
\hline DC & $\begin{array}{l}\text { "A scientific view that assumes that consciousness arises from reentrant interactions } \\
\text { among neural populations must therefore conclude that it is the neural activity of the } \\
\text { dynamic core that is causal. If we call that activity } \mathrm{C} \text { and the qualia it entails } \mathrm{C} \text {, then } \\
\text { it is } \mathrm{C} \text { that is the cause of our actions and further } \mathrm{C} \text { events" (133) }\end{array}$ & Causal \\
\hline TCL & $\begin{array}{l}\text { "consciousness is an oneiric-like internal functional state modulated rather than gen- } \\
\text { erated, by the senses" (135) "consciousness (i.e. being awake and able to feel, judge } \\
\text { and remember) is but one functional state of our brain" (135) "functional states such } \\
\text { as wakefulness or REM sleep and other sleep stages are prominent examples of the } \\
\text { breadth of variation that self-generated brain activity will yield" (134) }\end{array}$ & Functional \\
\hline ERE & $\begin{array}{l}\text { "causal-explanatory relationship is one-way, from internal neural events to conscious } \\
\text { experience. We propose a more expansive, two-way account...(1) that as a result } \\
\text { of the generic feature of 'emergence' in complex systems, one can expect there to } \\
\text { be two-way or reciprocal relationships between neural events and conscious activity; } \\
\text { and (2) that the processes crucial for consciousness cut across brain-body-world divi- } \\
\text { sions, rather than being brain-bound neural events" (44) "First, there is local-to-global } \\
\text { determination or 'upward causation' as a result of which novel processes emerge that } \\
\text { have their own features, lifetimes and domains of interaction. Second, there is global- } \\
\text { to-local determination, often called 'downward causation', whereby global character- } \\
\text { istics of a system govern or constrain local interactions" (44) }\end{array}$ & $\begin{array}{l}\text { Neither } \\
\text { causal nor } \\
\text { functional }\end{array}$ \\
\hline $\mathrm{BE}$ & $\begin{array}{l}\text { This theory is based on dualism. The "function-causal structure" distinction does not } \\
\text { apply. }\end{array}$ & $\begin{array}{l}\text { Neither } \\
\text { causal nor } \\
\text { functional }\end{array}$ \\
\hline OrchOR & $\begin{array}{l}\text { "Consciousness results from discrete physical events; such events have always ex- } \\
\text { isted in the universe as non- cognitive, proto-conscious events, these acting as part of } \\
\text { precise physical laws not yet fully understood. Biology evolved a mechanism to or- } \\
\text { chestrate such events and to couple them to neuronal activity, resulting in meaningful, } \\
\text { cognitive, conscious moments and thence also to causal control of behavior." (137) }\end{array}$ & $\begin{array}{l}\text { Causal (on } \\
\text { the ba- } \\
\text { sic level } \\
\text { of proto- } \\
\text { consciousness) } \\
\text { functional } \\
\text { with respect } \\
\text { to higher } \\
\text { forms of } \\
\text { conscious- } \\
\text { ness (via. } \\
\text { orchestra- } \\
\text { tion) }\end{array}$ \\
\hline HOT & $\begin{array}{l}\text { "Causal connections are irrelevant here, since there need be no causal tie between a } \\
\text { HOT and its target. Rather, HaTs result in conscious qualities because they make } \\
\text { us conscious of ourselves as being in certain qualitative states, which results in the } \\
\text { subjective impression of conscious mental qualities" (143) }\end{array}$ & Functional \\
\hline $\mathrm{AST}$ & $\begin{array}{l}\text { "The attention schema theory goes beyond this idea in providing a specific functional } \\
\text { use for the brain to compute that type of information. The heart of the attention schema } \\
\text { theory is that there is an adaptive value for a brain to build the construct of awareness: } \\
\text { it serves as a model of attention."(144) }\end{array}$ & Functional \\
\hline
\end{tabular}


IIT "IIT then postulates that, for each essential property of experience, there must be a Causal corresponding causal property of the PSC. The postulates of IIT state that the PSC must have intrinsic cause-effect power; its parts must also have cause-effect power within the PSC and they must specify a cause-effect structure that is specific, unitary and definite." (139)

\begin{tabular}{|c|c|c|}
\hline GNW & $\begin{array}{l}\text { "Many cognitive theories share the hypothesis that controlled processing requires a } \\
\text { distinct functional architecture which goes beyond modularity and can establish flex- } \\
\text { ible links amongst existing processors. (...) Here we synthesize those ideas by pos- } \\
\text { tulating that, besides specialized processors, the architecture of the human brain also } \\
\text { comprises a distributed neural system or 'workspace' with long-distance connectiv- } \\
\text { ity that can potentially interconnect multiple specialized brain areas in a coordinated, } \\
\text { though variable manner (...) It would therefore be incorrect to identify the workspace, } \\
\text { and therefore consciousness, with a fixed set of brain areas. Rather, many brain ar- } \\
\text { eas contain workspace neurons with the appropriate long-distance and widespread } \\
\text { connectivity, and at any given time only a fraction of these neurons constitute the } \\
\text { mobilized workspace." (78) }\end{array}$ & Functional \\
\hline RPT & $\begin{array}{l}\text { "Recurrent processing has high explanatory power in accounting for important fea- } \\
\text { tures of conscious percepts, as there is a strong homology between the integrated } \\
\text { structure of perception and the structure of recurrent processing." (140) }\end{array}$ & Causal \\
\hline PPI & $\begin{array}{l}\text { "Internal state transitions posited by a computational explanation must then not only } \\
\text { be mapped to internal states of the system in question, but these internal states must } \\
\text { also be causally connected to the sensory input and behaviour figuring in the descrip- } \\
\text { tion of the input-output patterns that are to be explained. (...) it is likely that some } \\
\text { computing devices will never be conscious, regardless of which computations they } \\
\text { perform (e.g., desktop PC). Such systems might simulate consciousness, but will never } \\
\text { be conscious. (...) not all virtual machines that perform approximate Bayesian infer- } \\
\text { ence by encoding a probability distribution over external states, given blanket states, } \\
\text { are realised by physical machines with the same Markov blanket partition. If we keep } \\
\text { this mind, we can maintain a distinction between simulating and instantiating con- } \\
\text { sciousness, but still retain the hypothesis that the right computational properties are } \\
\text { sufficient for consciousness (Chalmers, 2011), if they are instantiated by the right kind } \\
\text { of system." (79) }\end{array}$ & Causal \\
\hline TTC & $\begin{array}{l}\text { "There may thus be a "neuronal-phenomenal correspondence" between phenomenal } \\
\text { features and the temporo-spatially expanded stimulus-induced activity... while concep- } \\
\text { tually it may be described as "isomorphism" (141) }\end{array}$ & Causal \\
\hline $\mathrm{CAN}$ & $\begin{array}{l}\text { "the limited syntax of the CA formalism is sufficient to implement memory, predic- } \\
\text { tive coding, active inference, attention, categorization and planning. These functions } \\
\text { emerge naturally, moreover, from asking what structure an RCA [i,e. a "reduced con- } \\
\text { scious agent"] must have in order for its perceptions to be useful for guiding action } \\
\text { within the constraints imposed by ITP." (80) }\end{array}$ & $\begin{array}{l}\text { Neither } \\
\text { causal nor } \\
\text { functional. } \\
\text { Conscious- } \\
\text { ness is } \\
\text { fundamen- } \\
\text { tal; all } \\
\text { cognition } \\
\text { arises as } \\
\text { function } \\
\text { of con- } \\
\text { sciousness } \\
\text { (but con- } \\
\text { sciousness } \\
\text { is not itself a } \\
\text { function of } \\
\text { anything) }\end{array}$ \\
\hline
\end{tabular}


Table 4. Target of explanations. Quality versus Quantity of consciousness.

\begin{tabular}{|c|c|c|}
\hline Model & Quotes & Classification \\
\hline$\overline{\mathrm{CKK}}$ & $\begin{array}{l}\text { "The primaries and the early events in an election would correspond roughly to the } \\
\text { preliminary unconscious processing. The winning coalition associated with an object } \\
\text { or event would correspond to the winning party, which would remain in power for } \\
\text { some time and would attempt to influence and control future events." (142) }\end{array}$ & Quantity \\
\hline $\mathrm{DC}$ & $\begin{array}{l}\text { "The framework position I have taken here is that consciousness consists of qualia, } \\
\text { by which I mean not just isolated submodalities of red, warm, etc., but also complex } \\
\text { scenes, memories, images, emotions; indeed, the entire rich panoply of subjective ex- } \\
\text { perience. If, as I have suggested, the neural systems underlying consciousness arose } \\
\text { to enable high order discriminations in a multidimensional space of signals, qualia } \\
\text { are those discriminations. Differences in qualia correlate with differences in the neu- } \\
\text { ral structure and dynamics that underlie them. Thus, for example, olfactory neurons } \\
\text { and their circuits differ from retinal neurons and circuits, and such differences seem } \\
\text { sufficient to account for differences in their respective qualia. "(133) }\end{array}$ & $\begin{array}{l}\text { Quality and } \\
\text { quantity } \\
\text { (however, } \\
\text { the model } \\
\text { does not put } \\
\text { forward any } \\
\text { mechanisms } \\
\text { behind } \\
\text { quality) }\end{array}$ \\
\hline TCL & $\begin{array}{l}\text { "Perhaps the most spectacular diference concerning global brain states is that between } \\
\text { wakefulness and dreamless sleep...these two events must be electrical in nature given } \\
\text { the large number of elements involved; electrical in the sense of the electrical activity } \\
\text { of neurons and the synaptic input that initiate or terminate such activity." (135) }\end{array}$ & Quantity \\
\hline ERE & $\begin{array}{l}\text { "only a balanced and disciplined account of both the external and experiential side of } \\
\text { an issue can make us move one step closer to bridging the biological mind-experiential } \\
\text { mind gap"(41) "Marked quantitative and qualitative differences are observed between } \\
\text { the 'perception'(upright face) and 'no perception' (upside-down face) conditions." } \\
\text { (44) "One strategy would be to precisely describe the ongoing cognitive activity by } \\
\text { obtaining refined verbal reports from human subjects. These should reveal subtle } \\
\text { changes in the subject's experience (conditioned, for instance, by his/her cognitive } \\
\text { strategy, attention level, and inner speech). This type of qualitative first-person data is } \\
\text { usually omitted from brain-imaging studies. We show that if methodological precau- } \\
\text { tions are taken when gathering first-person data, they can indeed be used to shed light } \\
\text { on cognition via a joint analysis with quantitative measures of neural activity." (85) }\end{array}$ & $\begin{array}{l}\text { Quality and } \\
\text { quantity }\end{array}$ \\
\hline $\mathrm{BE}$ & Cf. quote in Table 2. ("increasing momentary states of probability") & Quantity \\
\hline OrchOR & $\begin{array}{l}\text { "[I]n the Orch OR scheme, these events are taken to have a rudimentary subjec- } \\
\text { tive experience, which is undifferentiated and lacking in cognition, perhaps provid- } \\
\text { ing the con- stitutive ingredients of what philosophers call qualia. We term such } \\
\text { un-orchestrated, ubiquitous OR events, lacking information and cognition, 'proto- } \\
\text { conscious'.[...] Such OR events would have to be 'orchestrated' in an appropriate } \\
\text { way (Orch OR), for genuine consciousness to arise." (137) }\end{array}$ & Quantity \\
\hline HOT & $\begin{array}{l}\text { "...HOT eliminates the cumbersome task faced by local theories of having to explain } \\
\text { every distinct kind of phenomenology with a different first-order mechanism." "we } \\
\text { need to understand how nonconscious HOTs can result in conscious qualities." "...my } \\
\text { strategy is to explain a state's being a conscious state in terms of our being conscious } \\
\text { of that state in some particular way." (143) }\end{array}$ & Quantity \\
\hline AST & $\begin{array}{l}\text { "If you're not conscious of something, we all know from experience that you can still } \\
\text { sometimes find yourself reacting to it. Things go on under the surface of conscious- } \\
\text { ness. And in that condition, when you react unconsciously, you have no control over } \\
\text { that reaction. (...) It is folk psychology in which, with some circularity, consciousness } \\
\text { is the thing in me that, when conscious of something, allows me to consciously choose } \\
\text { how to react to that thing. The present theory provides a specific, underlying expla- } \\
\text { nation for these common folk intuitions. At the root of these effects is awareness as a } \\
\text { model of attention. Without awareness, without that model of attention, the control of } \\
\text { attention and therefore of behavioral reaction is poor."(144) }\end{array}$ & Quantity \\
\hline
\end{tabular}


IIT "IIT is an attempt to characterize consciousness mathematically both in quantity and in quality (...) According to IIT, a MICS specifies the quality of an experience and integrated information $\Phi_{\text {Max }}$ its quantity." (99). "this approach provides an initial account of phenomenal space, it may also serve as a starting point for investigating other aspects of the quality of experience and their physical correspondents (...) The oneto-one correspondence between phenomenal and physical properties (...) represents a first attempt to deploy the theory to account for the quality of experience" (84).

\begin{tabular}{|c|c|c|}
\hline GNW & $\begin{array}{l}\text { "This dynamical constraint suggests the existence of two thresholds in human infor- } \\
\text { mation processing, one that corresponds to the minimal stimulus duration needed to } \\
\text { cause any differentiated neural activity at all, and another, the 'consciousness thresh- } \\
\text { old', which corresponds to the significantly longer duration needed for such a neural } \\
\text { representation to be mobilized in the workspace through a self-sustained long-distance } \\
\text { loop." (78) "the following features of four unconscious states, that are causally very } \\
\text { different from each other: deep sleep, coma/vegetative states, epileptic loss of con- } \\
\text { sciousness, and general anesthesia under various agents. Surprisingly, despite their } \\
\text { very different mechanisms they share major common features. These include: (i) } \\
\text { widely synchronized slow waveforms that take the place of the fast and flexible in- } \\
\text { teractions needed for conscious functions; (ii) frontoparietal hypometabolism; (iii) } \\
\text { widely blocked functional connectivity, both corticocortical and thalamocortical; and } \\
\text { (iv) behavioral unconsciousness, including unresponsiveness to normally conscious } \\
\text { stimuli." (145) }\end{array}$ & Quantity \\
\hline RPT & $\begin{array}{l}\text { "Conscious and unconscious processing and the feedforward-feedback distinction (...) } \\
\text { Instead of attributing visual awareness to specific areas or pathways, it might be useful } \\
\text { to relate the conscious-unconscious dichotomy to the distinction between feedforward } \\
\text { and recurrent processing." (146). "Whereas the first type-to which we refer here } \\
\text { as perceptual integration-has been related to phenomenal consciousness (subjective } \\
\text { experience; refs. } 2,3 \text { ), the latter type of integration has been linked to access (or in } \\
\text { some views "true") consciousness (availability for report; refs. } 4,5 \text { ). In the current } \\
\text { study, we investigate whether perceptual integration is ontologically independent from } \\
\text { conscious access" (94). }\end{array}$ & $\begin{array}{l}\text { Quantity } \\
\text { and quality }\end{array}$ \\
\hline PPI & $\begin{array}{l}\text { "Our use of the word "sentience" here is in the sense of "responsive to sensory impres- } \\
\text { sions". It is not used in the philosophy of mind sense; namely, the capacity to perceive } \\
\text { or experience subjectively, i.e., phenomenal consciousness, or having "qualia'. Sen- } \\
\text { tience here, simply implies the existence of a non-empty subset of systemic states; } \\
\text { namely, sensory states. In virtue of the conditional dependencies that define this sub- } \\
\text { set (i.e., the Markov blanket partition), the internal states are necessarily 'responsive } \\
\text { to' sensory states and thus the dictionary definition is fulfilled. The deeper philo- } \\
\text { sophical issue of sentience speaks to the hard problem of tying down quantitative } \\
\text { experience or subjective experience within the information geometry afforded by the } \\
\text { Markov blanket construction." (147) }\end{array}$ & Quantity \\
\hline TTC & $\begin{array}{l}\text { "Based on various lines of empirical evidence, here we postulate the four dimen- } \\
\text { sions of consciousness (level/state, content/form, phenomenal/ experience, cogni- } \\
\text { tive/reporting) are mediated by four corresponding temporo-spatial neuronal mech- } \\
\text { anisms: (i) the neuronal mechanism of "temporo-spatial nestedness" accounts for the } \\
\text { level or state of consciousness; (ii) the neuronal mechanism of "temporo-spatial align- } \\
\text { ment" accounts for selecting the content and constituting the form of con- sciousness; } \\
\text { (iii) the neuronal mechanism of "temporo-spatial expansion" accounts for the phe- } \\
\text { nomenal dimension of consciousness, e.g. experience with qualia; (iv) the neuronal } \\
\text { mechanism of "temporo- spatial globalization" accounts for the cognitive dimension } \\
\text { of con- sciousness, e.g. the reporting of its contents" (141) }\end{array}$ & $\begin{array}{l}\text { Quantity } \\
\text { and quality }\end{array}$ \\
\hline
\end{tabular}


CAN "The first is the combination of phenomenal experiences, i.e., of qualia. For instance, Quality one's taste experiences of salt, garlic, onion, basil and tomato are somehow combined into the novel taste experience of a delicious pasta sauce. What is the relationship between one's experiences of the ingredients and one's experience of the sauce? (...) To propose that we represent the possible qualia of a conscious agent by a probability space is to propose that qualia convey information, since probability and information are (as Shannon showed) transforms of each other. It is also to propose that qualia need not, in general, exhibit other structures, such as metrics or dimensions. Now certain qualia spaces, such as the space of phenomenal colors, do exhibit metrical and dimensional properties. These properties are not precluded. They are allowed but not required. All that is required is that we can meaningfully talk about the information content of qualia." (36).

\section{Supplementary: Scoring Method}

Each author scanned representative literature for their assigned models and prepared a short summary highlighting the major assumptions, hypothesis and evidence supporting them. In this processes quotes were also selected. In parallel, each author reviewed the others selected literature. Later, during several meetings, summaries and personal notes were compared and discussed. Finally, each author assigned a value between 0 and 3 for each axis (according to Table 1). The result was averaged across the three authors (values are reported in Table 5), and became the heuristic position for models in Figure 2. Values were corrected to improve theoretical consistency in case the average would not be representative of the main intuitions behind models.

\begin{tabular}{llll}
\hline Model & Mode of explanation $( \pm)$ & Mechanism of explanation $( \pm)$ & Target of explanation $( \pm)$ \\
\hline \hline CK & 2.67 & 1.33 & -2.33 \\
\hline DC & -1.33 & 2 & 0 \\
\hline TCL & 2 & -0.5 & -1 \\
\hline ERE & -2 & 0 & 1.5 \\
\hline BE & 1 & 0 & -0.67 \\
\hline OrchOR & 2.5 & 0.5 & -1.75 \\
\hline HOT & 1 & -3 & -1 \\
\hline AST & -0.67 & -2.83 & -1 \\
\hline IIT & -2 & 3 & 1.7 \\
\hline GNW & 2 & -2.67 & -1.17 \\
\hline RPT & -1 & 2.5 & 0.2 \\
\hline PPI & -0.83 & 1.5 & -0.7 \\
\hline TTC & -0.33 & 0.5 & -0.33 \\
\hline CAN & -2.67 & 0 & 2 \\
\hline
\end{tabular}

Table 5. Average score models of consciousness. We report the average values plotted in Figure 2. This is given by the mean of the three authors score, considering corrections. A value of 1 corresponds to a slight commitment to the direction of the axis and a value of 3 to a strong commitment. The value 0 was used if the model did not qualify for the + or - direction. Directions are given by Table 1 . 